Portland State University

PDXScholar

8-25-2021

\title{
Multi-scale Environmental Conditions Associated with Shade-Tolerant Conifer Regeneration in Forest Park, Portland, Oregon
}

Matthew Cook

Portland State University

Follow this and additional works at: https://pdxscholar.library.pdx.edu/open_access_etds

Part of the Forest Management Commons

Let us know how access to this document benefits you.

Recommended Citation

Cook, Matthew, "Multi-scale Environmental Conditions Associated with Shade-Tolerant Conifer Regeneration in Forest Park, Portland, Oregon" (2021). Dissertations and Theses. Paper 5767.

https://doi.org/10.15760/etd.7638

This Thesis is brought to you for free and open access. It has been accepted for inclusion in Dissertations and Theses by an authorized administrator of PDXScholar. Please contact us if we can make this document more accessible: pdxscholar@pdx.edu. 
Multi-scale Environmental Conditions Associated with Shade-Tolerant Conifer Regeneration in Forest Park, Portland, Oregon

by

Matthew Cook

A thesis submitted in partial fulfillment of the requirements for the degree of

\author{
Master of Science \\ in \\ Environmental Science and Management
}

Thesis Committee:

Jennifer Morse, Chair

Andrés Holz

Jeffrey Gerwing

Portland State University

2021 


\begin{abstract}
Forest Park is a 5,100-acre urban forest located in Portland, Oregon, that has been impacted by various anthropogenic stressors including logging, fragmentation, invasive species, air pollution and recreation use due to its proximity to the urban environment. This legacy of land use coupled with natural disturbances has resulted in changes to forest structure, composition, and function - threatening the long-term sustainability of the park. Past research in Forest Park has identified a lack of regenerating shade-tolerant conifers, particularly western hemlock and western red cedar species, in the section of the park closest to the city. Typically, western hemlock and western red cedar typically establish later in Douglas-fir-western hemlock forest types in the Pacific Northwest and the successful regeneration of these species is a critical development process that leads toward multilayered canopy and structurally complex old-growth stand conditions. Achieving this old-growth condition in the park is one of the goals of current management activities which include, invasive species removal and replanting shade-tolerant conifers in degraded sections of the park. Since conifer recruitment dynamics are less understood in novel urban forests, these management actions would benefit from science-based guidance on current ecological conditions in the park.
\end{abstract}

In order to better understand conifer recruitment dynamics in this urban forest, a targeted sampling approach was utilized to find and monitor existing shade-tolerant conifer juveniles to characterize and quantify the multi-scale environmental habitat conditions at those sites as possible drivers of juvenile presence. Microsite factors associated with the presence of each juvenile species were modeled using a boosted regression tree approach. 
Vigor was qualitatively assessed for each juvenile sampled and vigor rankings were analyzed using topographic and stand level factors. Juveniles were typically observed in areas with less understory fern cover $(6-22 \%)$ than the surrounding area $(26-73 \%)$. Coarse woody debris was heavily associated with the presence of western hemlock juveniles with $84 \%$ of juveniles found established in downed nurse logs or stumps. Decreased litter cover was also significantly associated with western hemlock juveniles within the park units $(56-65 \%)$. At the stand level, decreased canopy cover density was associated with higher juvenile vigor for both species ( $95 \%)$ and decreased overstory density (191 trees/ha) was associated with higher vigor for western red cedar juveniles. Juveniles of both species were observed more frequently on north facing slopes and in park management units farther from urban environments. Based on these results, microsite, stand level, and site topographical factors need to be considered when implementing restoration techniques to promote natural regeneration of shade-tolerant conifers and identifying locations to plant new seedlings. 


\section{Acknowledgements}

Funding for field work and research was provided from a Faculty Enhancement Grant from Portland State University to Dr. Jen Morse. This research would not be possible without the support, guidance and encouragement from my advisor, Dr. Jen Morse. A huge thanks to my thesis committee member Dr. Andrés Holz, for regularly providing helpful feedback and direction. Thank you also to committee member Dr. Jeff Gerwing for always providing helpful feedback and assistance. Marshall Johnson, ecologist from Portland Parks \& Recreation, graciously and regularly offered up feedback, answered questions, and provided guidance throughout the project.

A big thanks to the Morse lab group and my ESM graduate student cohort for providing camaraderie and support throughout during this graduate school experience. This includes Erin McElroy, Olamide Alo, Alexandra Vargas Quiñones, Evan Suemori, Alex Bans, Trevor Williams, Kim Brown, Max Gersh, Allie Tissot and Elissa Connolly-Randazzo.

Thanks to Carole Hardy and ISS interns Scott Schlief, Joseph Gayaldo, and Stephen Ryan for all the great work and resources provided preceding my research allowing for an easier transition for myself to continue science-based inquiries into the ecology of Forest Park. Thank you to Dr. Yangdong Pan, Dr. Geoffrey Duh and Dr. Nancy Broshot.

Lastly, I would not be in this position without the love and support from my family, particularly my mother, stepfather, and dad. A special thanks to my partner and fiancée Olivia, for your unconditional love, support, and willingness to travel across the country with me while I pursue these academic goals. 


\section{Table of Contents}

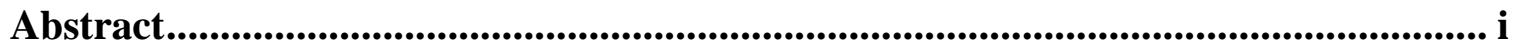

Acknowledgements .............................................................................................................. iii

List of Tables ................................................................................................... vi

List of Figures .......................................................................................................................... vii

Chapter 1: General Introduction ...........................................................................................1

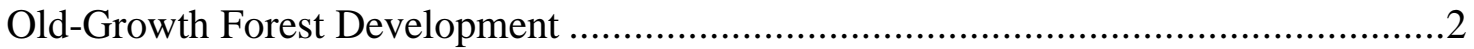

Human Impacts on Forest Development in the Pacific Northwest.................................3

Regeneration of Western Hemlock and Western Red Cedar ........................................

Western Hemlock Seed Availability..................................................................6

Western Hemlock Germination ........................................................................

Western Hemlock Seedling Establishment, Survival \& Growth.....................................

Western Red Cedar Seed Availability.................................................................

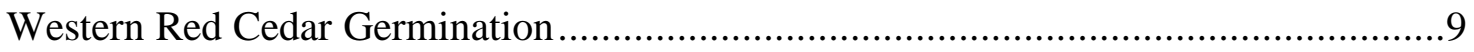

Western Red Cedar Seedling Establishment, Survival \& Growth ..............................10

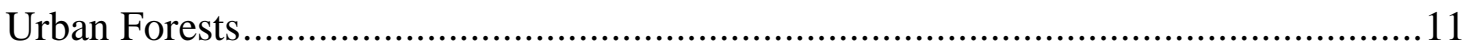

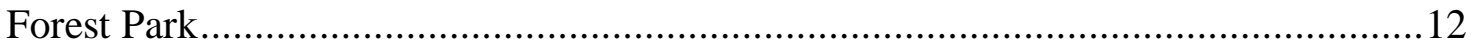

Chapter 2: Multi-Scale Growing Conditions Associated with Western Hemlock and Western Red Cedar in Forest Park, Portland, Oregon ....................................................16

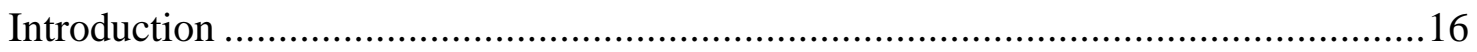

Study Objectives and Research Questions..............................................................17

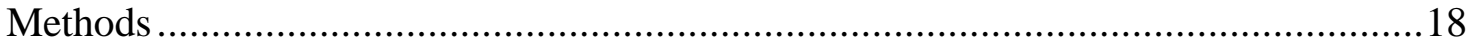

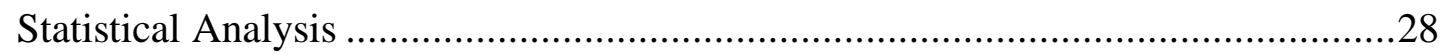

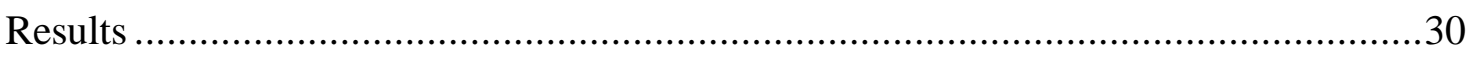

Vegetation Cover Effects on Juvenile Presence.......................................................33

Vegetation Cover at Western Hemlock Juvenile Sites ...........................................33

Vegetation Cover at Western Red Cedar Juvenile Sites ..........................................33

Forest Floor Substrate Effects on Juvenile Presence.................................................

Forest Floor Substrate Cover at Western Hemlock Juvenile Sites..............................35 
Forest Floor Substrate Cover at Western Red Cedar Juvenile Sites.....................36

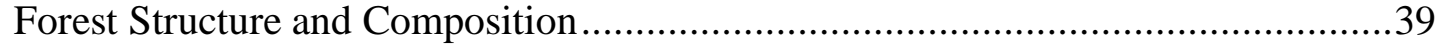

Forest Structure and Composition at Western Hemlock Juvenile Sites ................39

Forest Structure and Composition at Western Red Cedar Juvenile Sites ..............40

Shade-Tolerant Conifer Prevalence in Overstory ..............................................42

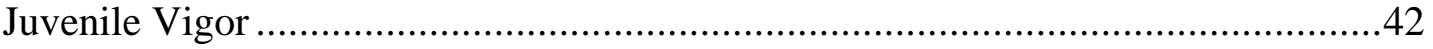

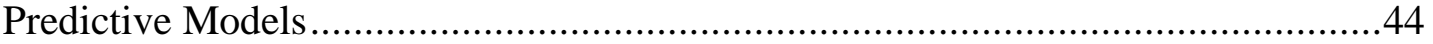

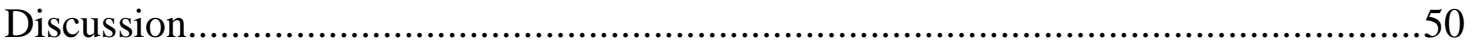

Microsite Level Factors - Vegetation Cover .................................................50

Microsite Level Factors - Substrate Cover.......................................................51

Microsite Model Performance.......................................................................53

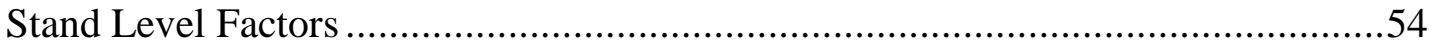

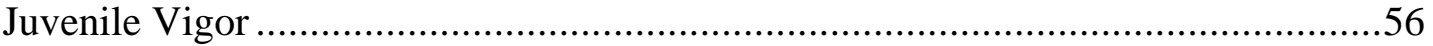

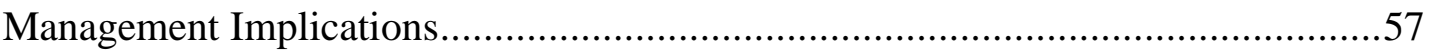

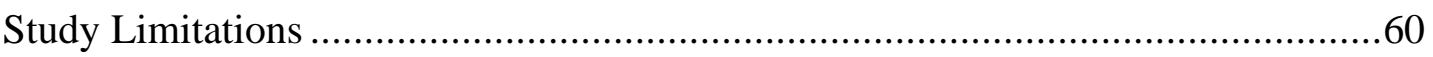

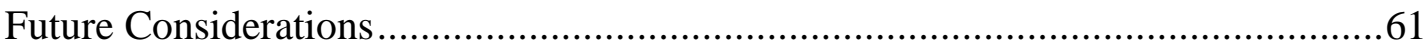

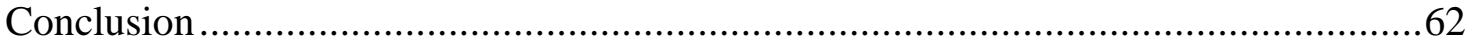

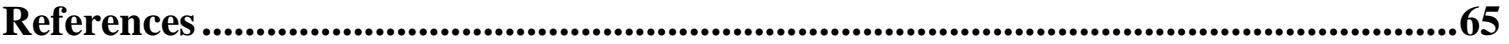

Appendix A

Canopy Gap Analyis.......................................................................................................................72 


\section{List of Tables}

Table 1. Abiotic and Biotic environmental variables measured at each plot location......26

Table 2. Qualitative variables measured during vigor assessment of juvenile conifers. ..27

Table 3. Number of juveniles of each target species observed per hour in each unit.......31

Table 4. Summary statistics of topographic variables measured at TSHE and THPL site

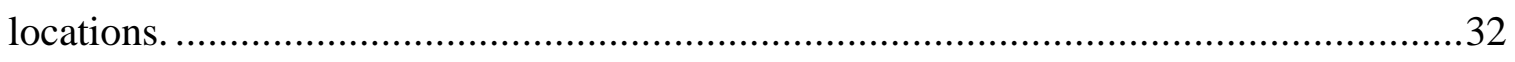

Table 5. Mean vegetation percent cover for each vegetation cover group.....................35

Table 6. Mean forest floor substrate cover measured at TSHE and THPL sites..........38

Table 7. Mean overstory density at TSHE and THPL site locations............................41

Table 8. Canopy cover density measured at each TSHE and THPL site locations..........41

Table 9. Shade-tolerant conifer overstory stand metrics and seed tree density...............42

Table 10. Mean stand level variables assessed for each juvenile species' vigor classes.. 43

Table 11. Microsite predictor variable influence and ranking for each species model. ...47

Table 12. Summary of evaluation metrics for both juvenile species BRT model...........49 


\section{List of Figures}

Figure 1. Conceptual model displaying environmental and species-specific factors that

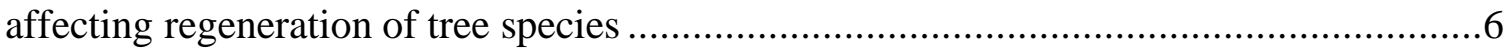

Figure 2. Juvenile site locations in each sample unit of Forest Park..........................19

Figure 3. Schematic of paired plot monitoring layout ..........................................21

Figure 4. Photo examples of paired microsite plots ..........................................22

Figure 5. Conceptual model displaying different hierarchal levels of environmental factors monitored at juvenile site locations. .....................................................24

Figure 6. Conceptual model of juvenile vigor class assessment analysis.....................28

Figure 7. Distribution of slope aspect positions recorded for each species in each unit. .32

Figure 8. Distributions of vegetation cover percentages by category observed at TSHE

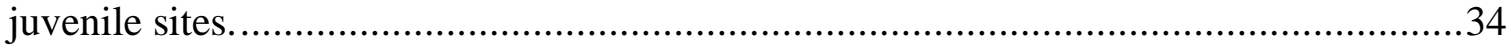

Figure 9. Distributions of vegetation cover percentages by category observed at THPL

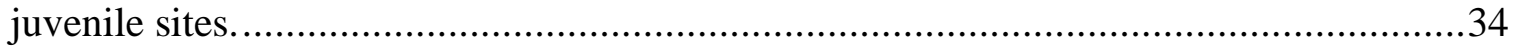

Figure 10. Distributions of vegetation cover percentages by category observed at TSHE

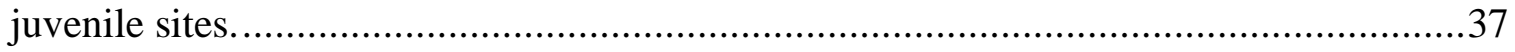

Figure 11. Distributions of vegetation cover percentages by category observed at THPL

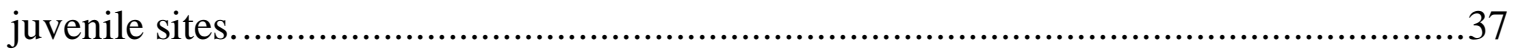

Figure 12. Stand density distributions by tree species in each sample unit observed at

TSHE sites.

Figure 13. Stand density distributions by tree species in each sample unit observed at

THPL sites 
Figure 14. Relative percentages of observed vigor class by species and sample unit.....43

Figure 15. Correlation coefficient matrix for all microsite environmental predictor variables used in the TSHE boosted regression tree model.

Figure 16. Correlation coefficient matrix containing for all microsite environmental predictor variables used in the THPL boosted regression tree model.

Figure 17. Partial dependency plots of probability of TSHE presence based on microsite predictor variables.

Figure 18. Partial dependency plots of probability of TSHE presence based on microsite predictor variables. 48

Figure 19. Three-dimensional partial dependence plots displaying the strongest interactions between predictor variables in each species model. 


\section{Chapter 1: General Introduction}

The successful regeneration of shade-tolerant conifer species, western hemlock (Tsuga hetereophylla), and western red cedar (Thuja plicata) is fundamental to the longterm sustainability of mixed-conifer forests in the Pacific Northwest (PNW). However, novel disturbance regimes introduced by humans have impacted natural ecosystems and interrupted important ecological processes. Impacts from land use change, habitat fragmentation, climate change, invasive species, and urbanization have altered natural tree regeneration processes and caused shifts in forest species composition (Dey et al. 2019). These anthropogenic stressors can be particularly impactful in urban forests based on their proximity to the urban environment and high population densities (Dwyer 2000; Nowak et al. 2010). Consequently, these impacts have created novel forest conditions that threaten the long-term resilience of forested ecosystems. Urban forest managers have been tasked to increase stand structural complexity, promote resilience, and restore natural ecosystem functioning. Knowledge regarding how current environmental conditions affect critical ecological processes such as tree regeneration in urban forests is currently lacking yet is needed to provide science-based guidance to management practices.

Western hemlock and western red cedar are two prominent late-successional conifer species present in the Douglas-fir (Pseudotsuga menziesii) dominated forests of the PNW. Both species are shade-tolerant and typically establish later in forest development after shade-intolerant pioneer species such as Douglas-fir. Shade-tolerance is a physiological characteristic of trees and refers to the ability of a tree species to undergo the stages of its life cycle in low-light conditions (Franklin 2018). In the absence of major 
disturbances, shade-tolerant species will typically replace more shade-intolerant species as forest develop over time (Franklin 2018). The presence of a multi-layer canopy with shadetolerant conifer species in codominant the overstory is indicative of a stand developing towards old-growth conditions (Freund et al. 2014; Franklin 2018). Understanding the dynamics of western hemlock and western red cedar regeneration is of critical importance for managers seeking to promote the development of managed stands towards structurally complex, old-growth conditions.

In recent decades, forest managers have been tasked to either protect existing oldgrowth reserves or to promote old-growth characteristics in younger stands. For example, the Northwest Forest Plan ended clearcutting of old-growth forests on federal land and emphasized the restoration of late-successional forests (Phalan et.al. 2019; USDA Forest Service; USDI Bureau of Land Management 1994). Retaining older patches of forest helps to provide wildlife habitat, seed sources, carbon sequestration and other ecosystem services (Spies and Franklin 1996; Schrader 1998). While there are many multifaceted benefits to increasing structural complexity and promoting old-growth conditions in PNW forests, but the development of old-growth forests is complex and takes centuries to unfold.

\section{Old-Growth Forest Development}

Franklin et. al. 2002 describes a broadly cited model of natural stand development using Douglas-fir-western hemlock forests of the PNW as an example. After large disturbances, early seral species such as Douglas-fir are the first to typically establish on the landscape during the cohort establishment phase. As these early pioneer species continue to grow, eventually their canopy overlap resulting in complete canopy closure of 
the stand. After canopy closure, stands typically undergo the biomass accumulation and competitive exclusion phase that is characterized by rapid growth, and density-dependent mortality or self-thinning. After stands have reached $80-100$ years in age, there is generally a transition into the maturation stage where pioneer canopy trees reach maximum height and crown diameter. At this stage, shade-tolerant species establish in the understory, although establishment rates are highly variable. In the following decades to centuries, vertical diversification occurs as the shade-tolerant species grow into co-dominant canopy positions creating a multi-layered canopy. Horizontal diversification occurs with increasing gap development and the increased dominance of shade-tolerant conifers. These are general stand development stages that lead towards structurally complex, old-growth forest conditions. The development of structurally complex forests is highly variable and can take centuries (Franklin \& Dyrness 1988). This model emphasizes the importance of structural features in addition to live trees and the impact that disturbance legacies leave on future stand development. However, post-Euro-American settlement forest stands in the PNW have experienced altered disturbance regimes that have excluded important legacy forest structures.

\section{Human Impacts on Forest Development in the Pacific Northwest}

Human-induced disturbance regimes have altered the natural development of Douglas-fir-western hemlock forests in the PNW (Franklin \& Dynress 1988; Spies et al 2002). Logging, grazing, introduction of non-native species, urbanization, and fragmentation have altered current forest structure and composition particularly near urban areas and valleys (Spies et al. 2002). Forest logging operations such as clearcutting are 
more frequent and intense than natural disturbances but less variable in size (Spies et al. 2002). The post-disturbance conditions associated with clear-cut logging differ from the conditions following natural disturbances (e.g., wildfires, windfall, insect/disease). Clearcutting practices remove all remnant seed trees as well as woody debris (Franklin et. al 2002). Remnant trees are important legacy structures left after disturbances as they influence the spatial patterns of establishing seedlings post-disturbance (Goslin 1997). Without important legacy forest structural components, conifer regeneration densities and rates in the Coast Range are highly variable following large-scale disturbances (Franklin et. al. 1981). Current patterns of forest structure and composition in the PNW have largely resulted from these impacts from human activities and are currently still driven by patterns in land ownership. Private forests are generally managed to maximize timber production while public forests are generally managed in a more ecologically holistic approach to support multiple uses. To that degree, understanding the dynamics of shade-tolerant regeneration is applicable for managers seeking to promote natural forest development in stands impacted by past human activities.

\section{Regeneration of Western Hemlock and Western Red Cedar}

Tree regeneration is defined as the renewal of a tree crop by self-sown seed or vegetative means and is a multi-stage process that includes seed production, seed dispersal, germination, seedling establishment, and seedling survival/growth (Oliver and Larson 1996; Ford-Robertson 1971). These individual stages and other site-specific environmental conditions necessary for establishment of new trees are referred to as the regeneration niche (Grubb 1977). The regeneration niche model implies that certain environmental conditions 
must be met in concurrence with individual regeneration processes for trees to successfully regenerate. One of the main tenets of the regeneration niche concept is that the physical environment combined with legacies of land use and disturbance that a seedling is exposed to, affects its probability of survival and recruitment into the stand (Dey et al. 2019).

There are different multi-scale biotic and abiotic environmental factors that can influence the probability for successful regeneration to occur for a tree species (Figure 1). These include factors that affect the microsite environment such as seedbed substrate, shading objects, vegetation cover, and litter depth. Factors affecting regeneration at the stand level include canopy cover density, stand density and presence of adequate seed sources. Landscape scale environmental factors in include slope, aspect, and slope position. The regeneration niche is species-specific therefore the requirements for western hemlock and western red cedar to successfully regenerate need to be investigated individually. Western hemlock and western red cedar are typically associated with old growth forests, but their rates of establishment and recruitment in PNW forests development are less known. Understanding the different environmental factors associated with the natural regeneration of these species can provide insights into old growth forest development and management practices. 


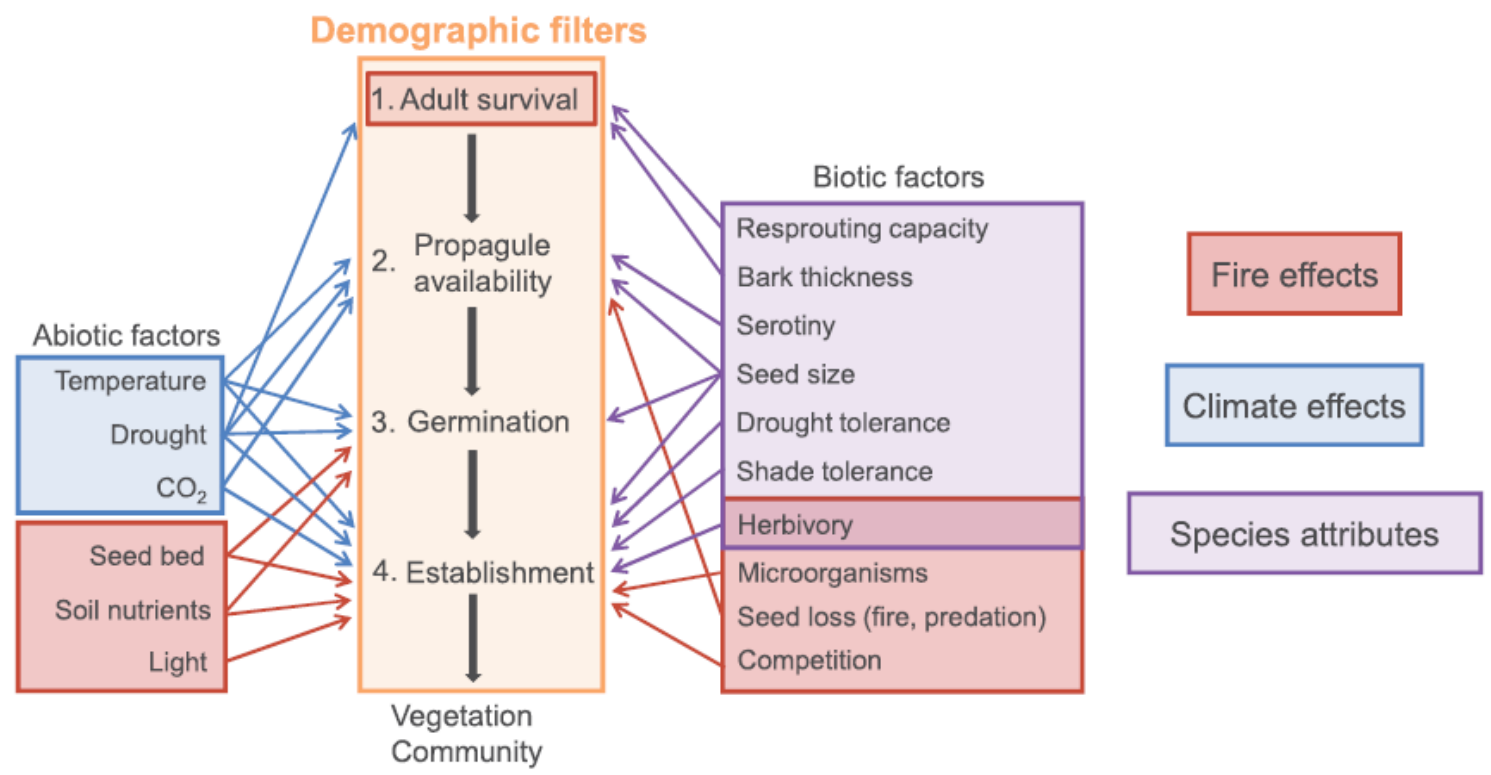

Figure 1. Conceptual model displaying environmental and species-specific factors that affecting regeneration of tree species. Adapted from Davis et al. 2018.

\section{Western hemlock seed availability}

Western hemlock is monoecious containing male and female reproductive structures on the same tree (Packee 1990). Flowering and pollination occur from mid to late April in western Oregon. The development of cones is variable, but cones typically mature by September - October with seeds falling shortly after (Packee 1990). Western hemlock is considered a good seed producing species with abundant cone crops beginning to occur when trees turn 15-30 years old (Colangeli and Owens 1990; Turner 1985). The number of viable seeds ranges from $10-20$ per cone with mast years occurring every 3-4 years. Good seed years can produce up to 20 million seeds per hectare from 100-year-old stands in coastal Oregon in mast years (Packee 1990). These seeds have large wings and can travel far distances from parent trees. In a $12.5 \mathrm{mph}$ wind, a seed released from a height of 200 feet can travel up to 2000 feet (Packee 1990). Factors that affect seed loss include 
ovule abortion, insufficient pollination, lack of fertilization and embryo degeneration (Colangeli and Owens 1990). Seeds are only viable during their first growing season (Packee 1990).

\section{Western hemlock germination}

Germination rates for western hemlock seeds are sensitive to temperature with an optimal temperature around $68^{\circ} \mathrm{F}\left(20^{\circ} \mathrm{C}\right)$, but seeds can germinate in temperature above freezing given sufficient time (Packee 1990). With adequate moisture, seeds germinate well on both organic and mineral substrates including duff, litter, rotten wood, or mineral soil (Packee 1990). It appears the principal requirement for western hemlock seed beds is adequate moisture and in drought conditions organic material can dry out before the seedling's radicle can reach the mineral soil and moisture (Packee 1990). However, decayed wood is an ideal substrate for germinates because of its moisture retention capacity, particularly in shaded environments (Harmon et al. 1986). The small seed size of western hemlock leaves it susceptible to desiccation particularly in certain exposed substrates such as litter or duff-making germination difficult (Haig et al. 1941). Heavy seed loss can occur via predation of small mammals, but predation rates can be highly variable (Gashwiler 1970; Harmon and Franklin 1989).

\section{Western hemlock seedling establishment, survival \& growth}

Western hemlock seedling establishment has been strongly associated with the presence of decayed logs, or "nurse" logs particularly in closed canopy forests (Harmon \& Franklin 1989; Gray 1997; Christy \& Mack 1984; Franklin \& Dyrness 1988) An experiment by Harmon and Franklin (1989) in Cascade Head on the Oregon coast found 
more western hemlock seedlings surviving on logs than on mineral soil in areas of similar moisture and vegetation. Competition with herbs and mosses on the forest floor appears to be responsible the abundance of seedlings found on nurse logs. In Christy and Mack's study (1984) in the Western Cascades, almost all western hemlock juveniles observed were rooted on decaying logs although logs covered only $10-30 \%$ of the forest floor. Decaying logs can provide a safe site from competing ferns, herbs, and mosses on the forest floor. Initial seedling growth is slow with 2 -year-old seedling typically less than 8 inches in height. Once seedlings establish with increased light conditions, it is not uncommon to observe average growth rates of 24 inches per year (Packee 1990).

Canopy gaps created after treefall can help facilitate juvenile establishment and growth due to increased soil moisture and light resources (Gray \& Spies 1996). Gap position is important for developing juveniles as northern edges of gaps receive more direct solar radiation which can negatively impact developing juveniles (Gray \& Spies 1996). Western hemlock seedling densities have been observed to be 3-9 times greater in gaps than in closed canopies within the same stand (Spies et al. 1990). Increased seedling growth has been observed with increasing gap size and increased seedling densities are typically associated with older gaps (Gray \& Spies 1996; Spies et al. 1990).

\section{Western red cedar seed availability}

The reproductive structures of western red cedar are classified as monoecious with separate male and female strobili on the same tree (Schopmeyer 1974). Pollination most commonly occurs in March with fertilization occurring in late May for trees located in the coastal region (Owens et al. 1984). Cones mature about 5 months after pollination and seed 
fall begins shortly after - typically from September - December (Minore 1990). Lack of pollination or pollen inviability are the major causes for reduced seed efficiency and seed loss (Colangeli and Owens 1990). Cones average around 3-6 seeds, but cones are commonly abundant and heavy seed crops common with a 3-4-year interval between large seed crops typical (Schopmeyer 1974; Owens 1995). Seeds are about 6 mm long with wings typically same size as the body (Schopmeyer 1974). Most seeds fall within 300 feet of parent trees (Minore 1990). Major seed fall occurs during October and November and average annual can vary from 247,000 to $2.470,00$ seeds per hectare in coastal forests (Minore 1990). Seed production typically begins when these trees reach 15-30 years old (Turner 1985). Western red cedar regeneration is typically not limited by lack of seed production.

\section{Western red cedar germination}

Germination of western red cedar seeds is most successful in light or moderate shade (Minore 1972). Minore (1972) observed average seed germination rates that were 2 times higher in low and moderate shade treatments versus heavy shade treatment in field plots located in the Cascade Head Experimental Forest. This study also examined organic substrate types (duff versus rotten wood) influence on seed germination and did not find any significant trends. However, some studies have indicated that germination success is influenced in part by substrate type. A study by Klinka and Feller (1998) found that the western red cedar seeds germinated more frequently and successfully on burned floor forest substrate compared to mineral soil and undisturbed forest floor substrates. Another study by Haig (1941) found that western red cedar seeds germinated 5-10 times more 
successfully on burnt and unburnt mineral soil compared to duff. Haig concluded that fluctuations in the moisture content of duff, particularly on exposed sites, coupled with the relatively small seed size of western red cedar could in part explain why seeds failed to germinate as successfully on duff substrates. Seeds have been shown to escape rodent and bird predation, but high mortality rates can occur during the germination phase. (Gashwiler 1967). Germination is unlikely to occur after the first year of seed fall (Minore 1990). Based on observations from growth chamber trials, seeds can germinate quickly, given warmer temperatures: $15-25^{\circ} \mathrm{C}$ (Harrington 2020). This ability to germinate quickly differs from other local conifer species such as Douglas-fir and allows for germination in the fall months given optimal temperatures.

\section{Western red cedar seedling establishment, survival \& growth}

As western red cedar typically produces abundant, viable seed crops that have high survival rates therefore it appears that seedling establishment and survival is a critical limiting stage in the life cycle of the species. Seedlings have been found to establish successfully on mineral soil in post-fire landscapes (Feller and Klinka 1998). Exposed mineral soil has been observed to be a favorable seedbed conditions for cedar establishment while heavy moss cover can limit establishment (Lepage et. al. 2000). Seedlings can establish on decaying wood, logs, and organic material (Christy and Mack 1984). Western red cedar seedlings benefit from partial shading because of the stress that drought and high temperatures can inflict on the juveniles.

Seedling establishment appears to be more successful in partially open areas and gaps compared to closed forest canopies (Spies et al., 1990). Canopy gap position has also 
been shown to affect seedling establishment due to the north-south shade gradient effect in northern hemisphere forests (Wright et. al. 1998). North ends of gaps are typically sunnier than the southern ends of gaps subsequently creating a soil moisture gradient within the canopy gap. Wright et. al. (1998) observed increased western red cedar seedling emergence and higher seedling survival in southern ends of canopy gaps compared to northern ends.

Shrub layers can inhibit the growth of seedlings in coast regions due to competition for forest floor nutrients and seedling growth has been observed to increase following shrub removal. (Messier 1993). Management of competing vegetation can improve the early development of western red cedar seedlings and saplings. Removal of competing vegetation has shown to increase the height of juveniles more effectively than removal of shading aboveground vegetation (Adams et. al. 1991). This indicates that transpiration related stress may be more critical component to western red cedar juvenile survival than light competition. Western red cedar is very shade tolerant and can endure long periods of suppressed growth in shaded, subordinate canopy positions (Wright 1998).

Western red cedar also can reproduce vegetatively. This can occur in three different types of vegetative reproduction: layering of lower branches, rooting from fallen branches and development from fallen trees (Minore 1990). Layering occurs when a branch of the tree touches the forest floor and eventually roots into the ground.

\section{Urban Forests}

Urban forests provide critical ecosystem services to local communities. Their importance continues to grow with $80 \%$ of the US population currently living within urban areas (Nowak 2010). These ecosystem services include carbon sequestration, air pollution 
removal, shading/cooling benefits, improved water quality, flood control, wildlife habitat, and cultural benefits (Nowak et al. 2006; Solecki et al. 2000; Dwyer et al. 1992; Bolund \& Hunhammar 1999). However, urban forests are subjected to additional stressors not experienced as heavily in remote, wildland forests and therefore are at greater risk of having natural ecological processes impacted or interrupted. These stressors include air pollution, fragmentation, invasive species, recreation use and urban heat island effect (Ballantyne et al. 2014; Stolte 1996; Pye 1988; Copp 2014). These anthropogenic disturbances alter natural forest developmental processes and can create novel forest conditions that ultimately lower the resilience of the ecosystem (Dwyer 2000).

These broad range of disturbances in the urban environment can impact tree regeneration and the long-term sustainability of urban forests. Invasive species are often more prevalent in urban ecosystems this can potentially impact plant recruitment. For example, English ivy can depress the diversity of local plant community, but plant communities can restore themselves following removal and persistence of native seeds in seedbank (Biggerstaff et. al. 2007). Seed availability can be a limiting factor affecting regeneration in urban forests because of dispersal limitations due to fragmentation and lack of seed source. A lack of recruitment of late successional species has been observed urban forests, possibly result of novel disturbance regimes introduced via urbanization and past land use history (Broshot 2007).

\section{Forest Park}

Forest Park is a 5,100-acre (2000 hectares) urban forest located in Portland Oregon and is managed by Portland Parks and Recreation (PPR). The park is situated along the 
eastern side of the Tualatin Mountains northwest of downtown Portland. Forest Park is 7 miles in length and ranges from $0.5-1.5$ miles in width (Broshot 1999). The Forest Park Natural Resource Management Plan was developed in 1995 and organized the park into three management units: south, central, and north (City of Portland 1995). These management units align with an urban to rural gradient with south management unit experiencing more recreation use and degradation. The park is heavily used for recreation including hiking, running and mountain biking with over 80 miles of trails. The park provides recreation opportunities for an estimated 550,000 visitors each year (Myers 2014; Van Deren et. al. 2018). The park is one of the largest natural areas within a city's limit nationwide (McAllister et al. 2011). Forest Park provides numerous ecosystem services to the community including clean air and water, flood control, wildlife habitat, climate regulation, biodiversity, and recreation. (Meyers 2013). Forest Park also serves as a wildlife corridor connecting the Portland metro region to the Coast Range. This habitat connectivity component of the park is critical for species dispersal throughout northwest Oregon by allowing plants and animals to carry out life functions in more suitable habits (Meyers 2013). The long-term sustainability of Forest Park is crucial to maintain these important ecosystem services in the region.

Forest Park is located within the western hemlock vegetation zone and is connected to the Oregon Coast Range (Franklin and Dyrness 1988). As a result of logging and land use practices, this vegetation zone is dominated by early seral species such as Douglas-fir (Pseudotsuga menziesii) (Spies et al. 2002). Over time and in the absence of major disturbance, later succession species such as western hemlock and western red cedar dominate the landscape. However, this is exceedingly rare as these forests are subject stand 
replacing wildfire disturbance events with a fire return interval before Euro-American settlement estimated at around 200-300 years (Franklin 2018). Other common tree species in Forest Park include grand fir (Abies grandis), bigleaf maple (Acer macrophyllum), red alder (Alnus rubra), pacific yew (Taxus brevifolia), and cascara (Rhamnus purshiana). The park experiences a maritime climate characterized by wet winters, dry summers, and mild temperatures all year (Franklin \& Dynress 1988).

Forest Park's history has been strongly characterized by human activities in the region. In the early nineteenth century, indigenous groups occupied regions along the banks Lower Columbia and Lower Willamette Rivers-including two villages in present day Portland (DeVoto 1953). Indigenous groups were composed of several branches of the Chinookan-speaking people including those of the Multnomah, Kathlamet, Clackackamas, Chinook, Tualatin Kalapuya and Molalla. European settlers arrived in the region in the early 1800's and began clearing for settlement and agriculture (Munger 1960). By the mid1800's settlers had developed trails through the Tualatin Mountains to transport and trade crops to settlements along the Willamette River. The development of land for residential use gradually increased around the Tualatin Mountains along flatter ridge tops and bases while the steeper hills were logged by residents. These land use patterns continued into the $20^{\text {th }}$ century as the hills of west of Portland were continually logged by early settlers (Houle 1988). By the early $20^{\text {th }}$ century, most of the landscape making up Forest Park today had been clear cut. In addition to logging activities, the park has experienced three major wildfire events in 1889, 1940 and 1951 (Munger 1960). These wildfires cumulatively impacted over 1200 acres within the park, impacting the central unit of the park the most heavily (Houle 1988; Munger 1960). 
Recent research in Forest Park has identified differing forest structure and composition on an urban to rural gradient. The abundance of deciduous canopy cover, bigleaf maple and red alder, is most notable in the south and central sections of the park (Broshot 2007). Urban sections of the park also lack standing dead trees (Dresner et al. 2017). Lower amounts of coarse woody debris have been observed in the south unit of the park compared to north unit and reference site (Addessi 2017). Invasive species such as English ivy (Helix hedera) has increased in south sections of the park and has displaced native understory species (Copp 2014; Butler 2019). A lack of recruitment of shadetolerant conifer species has been observed in the park, particularly in sections of park closest to urban proximity has led to concern over the successional trajectory of the park (Broshot 2007; Dresner et al. 2017). 


\section{Chapter 2: Multi-scale Growing Conditions Associated with Western Hemlock and Western Red Cedar in Forest Park, Portland, Oregon}

\section{Introduction}

Urban forests are impacted by novel disturbance regimes introduced by humans that impact natural ecological processes such as tree regeneration. One of the largest urban forests in the United States is Forest Park, a large second-growth urban mixed-conifer forest in Portland, Oregon, whose recent history is characterized by human activities and disturbances. Tree regeneration is one ecological process that is of concern in urban mixedconifer forests like Forest Park. Past land use history and disturbances have created a heterogenous composition of stands associated with different dominant vegetation types and successional stages within the park (Broshot 2007; McAllister et al. 2011), but one specific issue that has been documented in certain sections of the park is a lack of shadetolerant conifer recruitment (Broshot 2007; Dresner et al. 2017). In much of Forest Park, this recruitment may be limited by the availability of legacy forest structural components such as remnant seed trees, snag trees and downed woody debris that are necessary for subsequent successional stages to occur. In addition, the park has been impacted by urbanization including effects of fragmentation, invasive species, and recreation use (Broshot 2007; Prather 2014; Van Winkle 2014). These impacts have resulted in forest conditions that constitute a novel state and differ from those of pre-Euro-American settlement stands (Christy et al. 2008), leading to concerns over the trajectory and future stand development in the park. 
Current management goals in the park include promoting structural diversity and setting vegetation trajectories towards structurally complex, old-growth conditions (McAllister et al. 2011; City of Portland 1995). The recruitment of shade-tolerant conifers such as western hemlock and western red cedar can help to achieve those management goals. However, the scarcity of western hemlock and western red cedar species present management challenges. Current management efforts include removal of invasive species and replanting seedlings of shade-tolerant species in degraded areas of the park. These restoration activities would benefit from science-based guidance on current ecological conditions in urban forests, because recruitment dynamics that are well understood based on decades of research in less disturbed forests may not be as predictable in the novel, understudied context of degraded urban forests in a changing climate. Therefore, to address the knowledge gap regarding western hemlock and western red cedar juvenile establishment and survival in urban forests, this study will examine multi-scale environmental conditions associated with naturally regenerated juveniles of each species in Forest Park.

\section{Study Objectives and Research Questions}

This research builds on previous studies that have identified a lack of recruiting shade-tolerant conifers, particularly in the sections of the park closest to urbanized areas. This study seeks to further understand and characterize the multi-scale environmental conditions associated with shade tolerant conifer regeneration in Forest Park by addressing the following research questions: 
1. What are the environmental conditions associated with the establishment and recruitment western hemlock and western red cedar juveniles?

2. Are the environmental conditions associated with the regeneration of western hemlock and western red cedar similar in different park management units?

3. What environmental predictor variables best predict presence of western hemlock and western red cedar regeneration?

4. What environmental factors contribute to low and high vigor in western hemlock and western red cedar juveniles?

Because effective forest management actions rely on accurate estimates of current ecological conditions, the results of this study will provide insights into shade-tolerant conifer regeneration in Forest Park along with recommendations to inform future management decisions.

\section{Methods}

To investigate the patterns of conifer regeneration in areas of Forest Park that were differentially affected by human activities, study locations were chosen to align with an urban-rural gradient using the Portland Parks and Recreation (PP\&R) defined management unit boundaries. Plot locations were installed in the south and north management units as well as the Burlington unit (Figure 2). The south management unit (1,236 acres), located between W. Burnside Road and Firelane 1, nearest to NW Portland and receives the most recreation use, and has been the focus of recent restoration efforts. The north management unit (1,558 acres), located between Germantown Road and Newberry Road, is further from the city and receives fewer visitors as a result. Plots were also installed in a 38-acre, old 
growth preserve owned by the Forest Park Conservancy, referred to as the Burlington unit in this study. While this preserve does not meet the technical definition of an old growth stand because it has too few large tree, snags, downed logs, and the stand is too small (Franklin \& Dyrness 1988), However, the Burlington unit does contain some very large, Douglas-fir trees, some older than 400 years, and contains many structural components consistent with old growth conditions (Broshot 2007). Furthermore, because it has not been impacted by logging or wildfires in recent centuries (Broshot 1999), the Burlington unit was used as a reference control to compare results from the north and south management units. Plots were established and data collection occurred from summer 2019 through fall 2020.

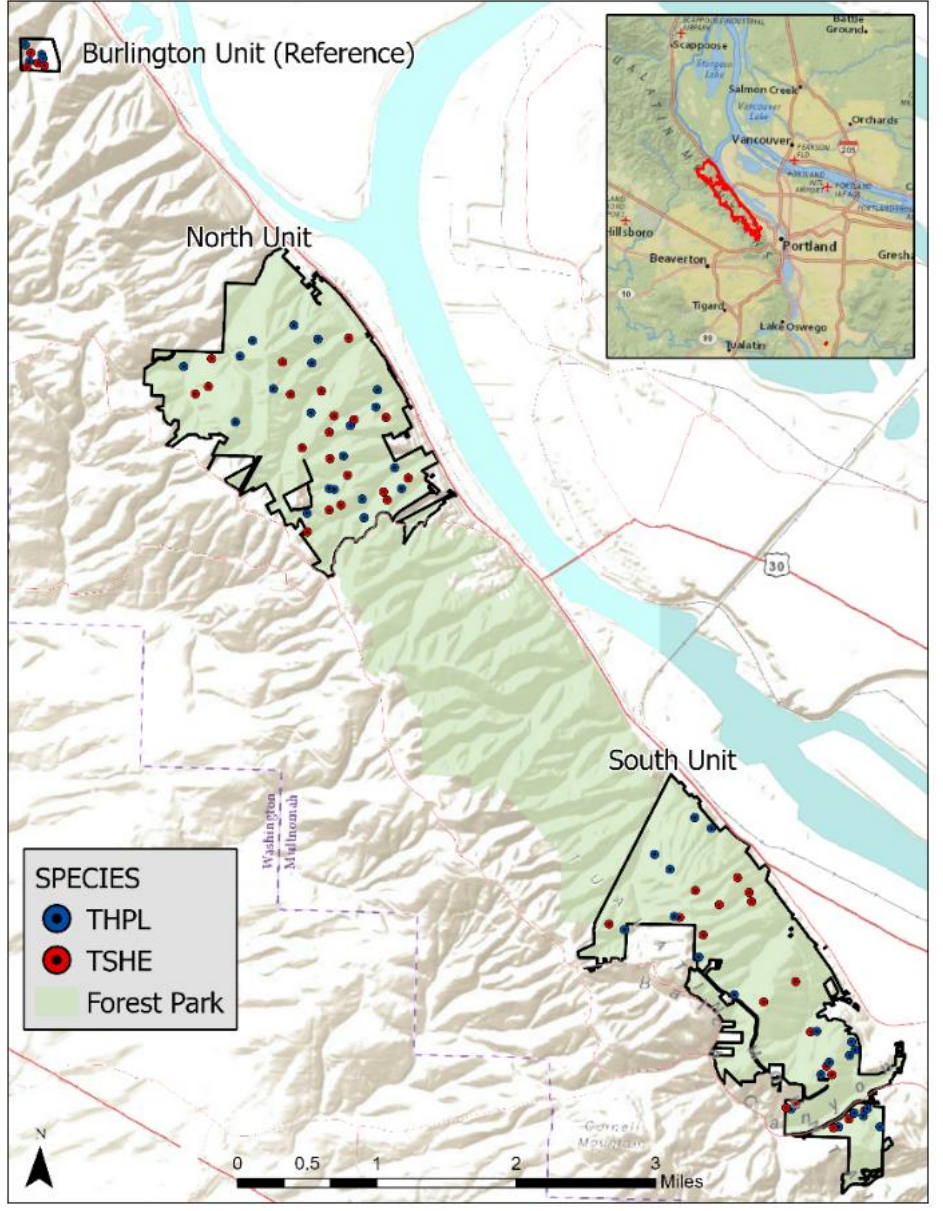

Figure 2. Juvenile site locations in each sample unit of Forest Park. Blue points represent western red cedar (THPL) sites, and the red points represent western hemlock (TSHE) sites. 
Due to the scarcity of shade-tolerant juveniles in the study area, a targeted field sampling approach was utilized for field sampling. Juveniles were searched away from trails within the three sample units: north, south, and Burlington (reference). Juvenile encounter frequency was used as a co-variate of overall juvenile landscape abundance per species. Encounter frequency was calculated by tracking total search time and number of individuals observed on sampling track. Encounter frequency was tracked within each management unit and dominant overstory vegetation type. Plot locations were selected to ensure: 1) a representative amount of juvenile growth forms (seedling vs sapling) and 2) a proportional number of plots in each dominant overstory vegetation type present in the park. Juvenile conifers were categorized either as seedlings—individuals less than 1.37 meters in height or saplings - individuals greater than 1.37 meters in height with diameters less than $12.7 \mathrm{~cm}$ (U.S. Forest Service 2020). Dominant overstory vegetation types were categorized in three groups for this study: mixed-conifer, mixed-conifer-deciduous and deciduous. Plots were installed at the site of the target juvenile conifer. Areas of recent replanting efforts were identified, and locations with transplants were not chosen for sampling or factored into search time calculations.

After a juvenile conifer was identified for sampling, a plot center was established at the location of the juvenile. Topographical variables such as slope, aspect, and slope position were measured at the plot center. Next, paired $1 \mathrm{~m}^{2}$ microsite plots were established at 1) the juvenile conifer (plot center) and 2) a randomly placed location $\sim 1-2$ meters from the juvenile (Figures $3 \& 4$ ). The microsite plot installed around the juvenile conifer is referred to as the "regeneration" microsite and it is associated with the presence of the target conifer 
species. The microsite plot randomly installed $\sim 1-2$ meters away from the juvenile is referred to the "control" microsite plot and is associated with the absence of the target conifer species. The placement of the control microsite was determined by a random number generator that generated a random integer from 0-360, and that number was used as the compass azimuth for placing the control plot. If the control microsite landed on another target juvenile conifer species, a new random azimuth direction was generated, and the plot was placed again. Microsite plots were monitored using quadrat frame and the quadrat frame was aligned toward the cardinal directions when placed around each juvenile.

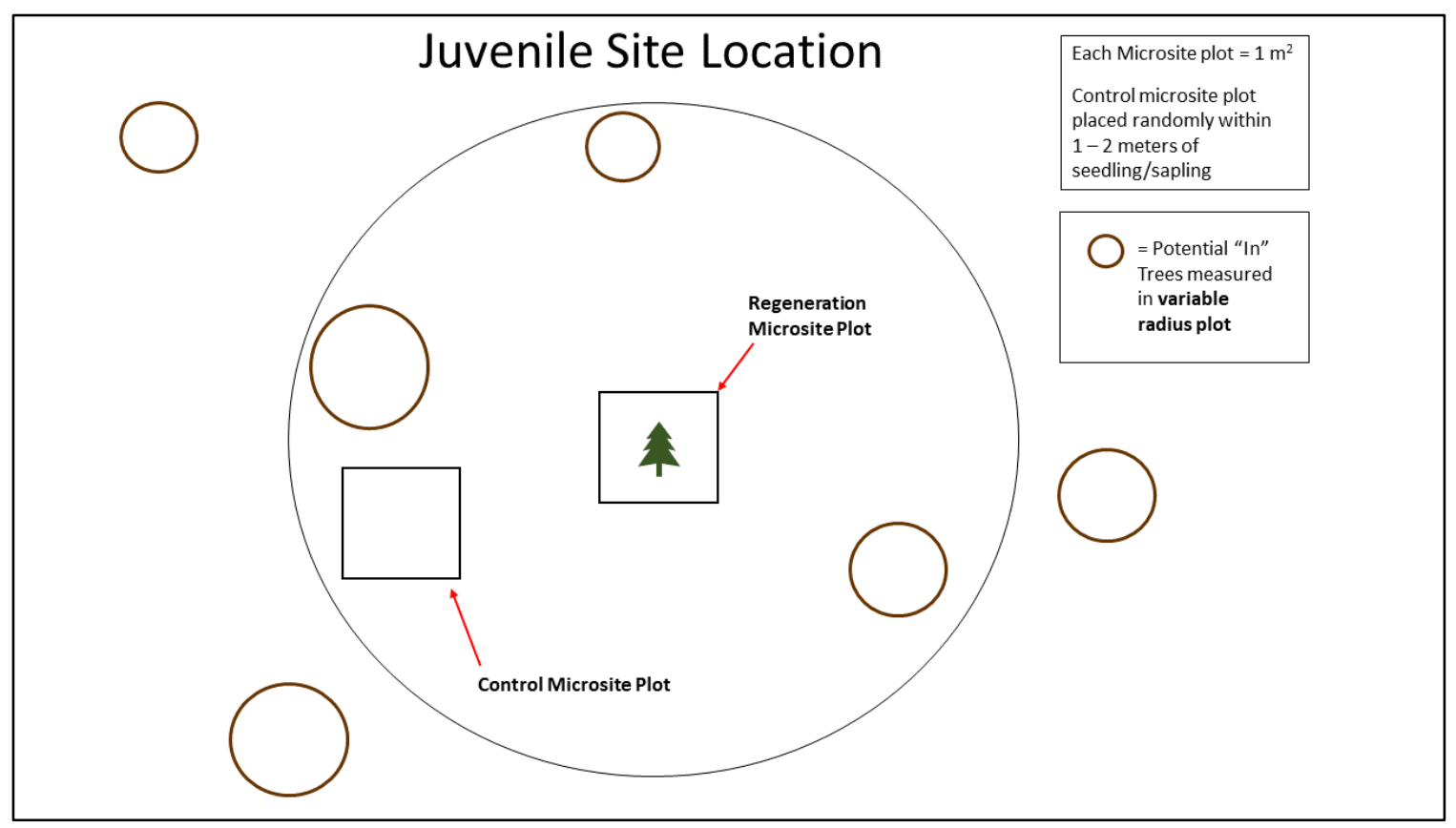

Figure 3. Schematic of paired plot monitoring layout. Regeneration microsite plot installed around seedling/sapling and a control microsite plot installed randomly within 1-2 meters. Tree density and basal area measured around regeneration microsite plot using variable radius plot method. 

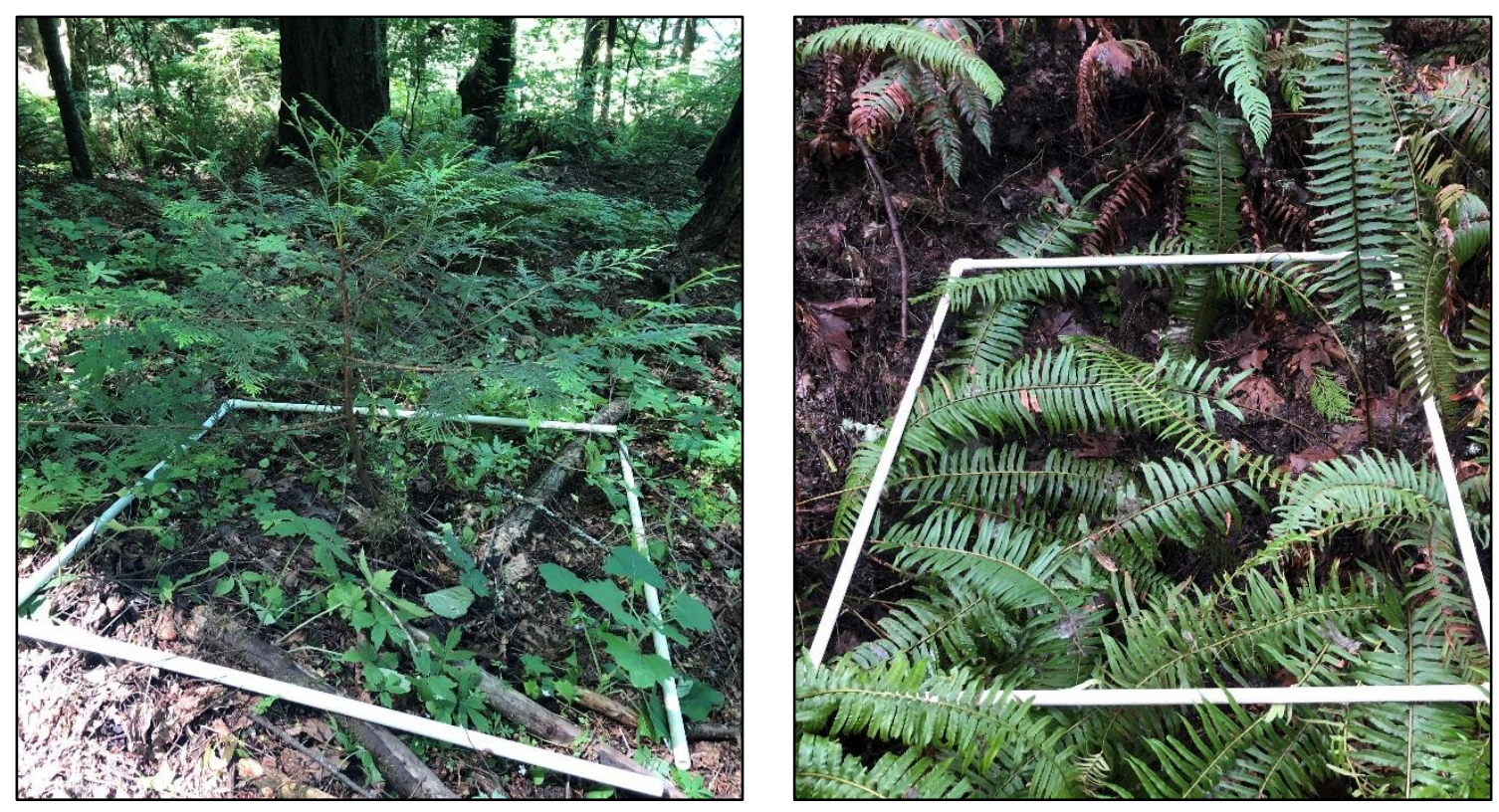

Figure 4. The photo on the left displays an example of a regeneration microsite plot and the photo on the right displays an example of a control microsite plot.

After plot establishment different multi-scale environmental factors were measured (Figure 5; Table 1). Visual estimates were made to the nearest percent for vegetation and forest floor substrate cover using a $1 \mathrm{~m}^{2}$ quadrat at each microsite plot location. Vegetation cover was recorded according to the following categories: herbaceous (forbs and grasses), shrubs (plants with woody stems), English Ivy (Helix hedera) and ferns. Forest floor substrate cover was categorized as rock, bare soil, litter, duff, moss, coarse woody debris (CWD), and fine woody debris (FWD) (Table 1). Coarse woody debris was defined as downed wood in the 1000-hour fuel class, greater than $7.6 \mathrm{~cm}$ (3 in) diameter (Harmon et al. 1986). Fine woody debris was defined as 1-, 10- and 100-hour fuels or downed woody material less than $7.6 \mathrm{~cm}$. Litter and duff depth measurements were also taken at the base of each juvenile and at random in the control microsite plots. Four litter and duff measurements were recorded and averaged in each microsite plot. Canopy cover density was recorded at both microsite plots using a densiometer. Canopy cover measurements 
were recorded at each cardinal direction around the juvenile's canopy extent, and the values were then averaged at each juvenile site. The following hypotheses were tested for paired microsite plots:

- Hypothesis 1: Regeneration microsite plots will have a dissimilar vegetation cover, forest floor substrate coverages and litter/duff depths compared to the control microsite plots.

- Hypothesis 2: Regeneration microsite plots will have a lower canopy cover density (more open) than the control microsite plots.

Tree density and basal area were measured around the juvenile sample using a variable radius plot or point sampling method. Variable radius plots are commonly used in forest inventory assessments and provide a rapid method to assess tree basal area and density (Hovind \& Rieck 1961; Shiver \& Borders 1996). In this method a basal area factor prism is used select "in" trees to measure in the plot. Diameter at breast height (DBH) was then measured for each "in" tree. Individual juvenile characteristics such as height and diameter were also measured. 


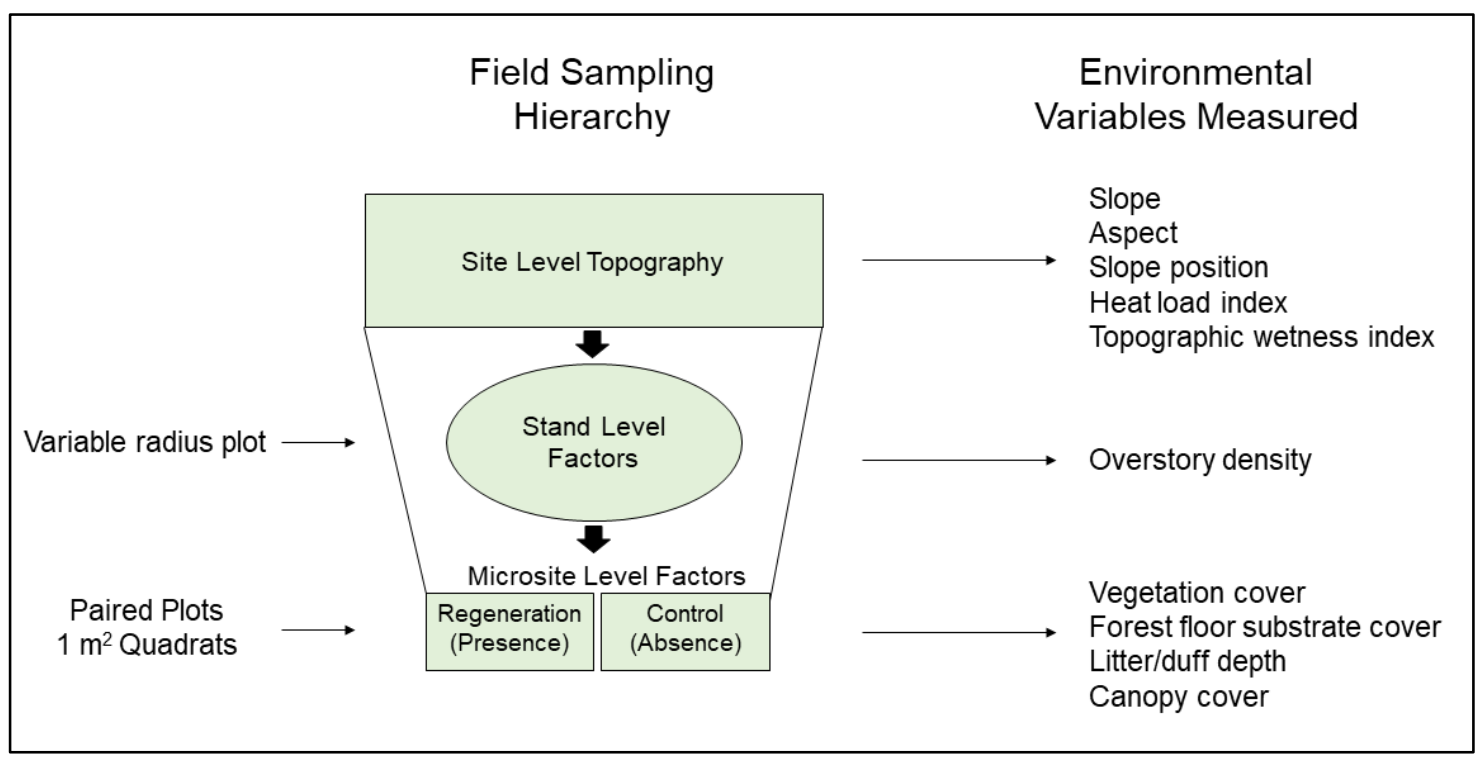

Figure 5. Conceptual model displaying different hierarchal levels of environmental factors monitored at juvenile site locations.

Since tree regeneration is strongly affected by temperature and soil moisture, topographic components such as slope, slope position and aspect were also measured at each plot location. In the northern hemisphere, southwest slopes are typically associated with drier and hotter conditions while northwest slopes are typically associated with cooler and wetter conditions. McCune and Keon (2002) developed the heat load index (HLI) to account for direct solar radiation input throughout a given landscape. This method transforms aspect and slope to produce a heat load index value from 0 (coolest) to 1 (hottest). A HLI raster layer was derived from a $1 \mathrm{~m}^{2}$ digital elevation model (DEM) for each of the three sample units. The DEM layer was derived from a 2014 LiDAR flyover point cloud data courtesy of the Oregon Department of Geology and Mineral Industries (DOGAMI). Topography also influences hydrological and geomorphological processes that affect soil moisture. A steady state wetness index called topographic wetness index 
(TWI) is a function of both slope and the upstream contributing area of a given location on a landscape can be used to model aspects of the local hydrology. TWI is highly correlated with soil attributes such as horizon depth, silt percentage, and organic matter content and aims to model soil water content (Moore et al. 1991). A raster layer of TWI was derived using a $1 \mathrm{~m}^{2}$ DEM for each sample unit. Additionally, Slope position was also recorded at the juvenile site location. This refers to the general location of the established juvenile conifer on the hillslope. The following categories were used: crest, upper slope, middle slope, lower slope, toe slope, depression, and level. Slope position can influence spatial variation of soil properties throughout the landscape by controlling the movement of water and material on the hillslope. 
Table 1. Environmental variables measured at each plot location. Vegetation and forest floor substrate cover variables measured in $1 \mathrm{~m} 2$ quadrat around juvenile conifer and control site.

\begin{tabular}{|c|c|c|c|}
\hline Category & Variable & Method of Measurement & Units \\
\hline \multirow[t]{6}{*}{ Abiotic } & $\begin{array}{l}\text { Heat Load Index (HLI) } \\
\text { Topographic Wetness }\end{array}$ & Derived from $1 \mathrm{~m}^{2} \mathrm{DEM}$ & Unitless \\
\hline & Index (TWI) & Derived from $1 \mathrm{~m}^{2} \mathrm{DEM}$ & Unitless \\
\hline & Aspect & Field Measured (Compass) & Degrees \\
\hline & Slope & Field Measured (Clinometer) & Degrees \\
\hline & Mineral Soil Cover & $\begin{array}{l}\text { Field Measured ( } 1 \mathrm{~m}^{2} \text { quadrat, visually } \\
\text { estimated) }\end{array}$ & $\%$ \\
\hline & Rock Cover & $\begin{array}{l}\text { Field Measured ( } 1 \mathrm{~m}^{2} \text { quadrat, visually } \\
\text { estimated) }\end{array}$ & $\%$ \\
\hline \multirow[t]{8}{*}{ Biotic } & Tree Density & $\begin{array}{l}\text { Field Measured (Variable Radius Plots } 2 \\
\text { M BAF) } \\
\text { Field Measured (Variable Radius Plots } 2\end{array}$ & Trees ha-1 \\
\hline & Tree Basal Area & M BAF) & $\mathrm{m}^{2} \mathrm{ha}^{-1}$ \\
\hline & Canopy Cover Density & $\begin{array}{l}\text { Field Measured (Densiometer, } 4 \\
\text { measurements averaged) }\end{array}$ & $\begin{array}{l}\% \text { Canopy } \\
\text { Cover }\end{array}$ \\
\hline & $\begin{array}{l}\text { Understory Vegetation } \\
\text { Cover }\end{array}$ & $\begin{array}{l}\text { Field Measured ( } 1 \mathrm{~m}^{2} \text { quadrat, cover } \\
\text { classes organized by functional group or } \\
\text { species of interest - Shrub, Herbaceous, } \\
\text { Fern and Ivy) }\end{array}$ & $\%$ \\
\hline & $\begin{array}{l}\text { Coarse \& Fine Woody } \\
\text { Debris }\end{array}$ & $\begin{array}{l}\text { Field Measured ( } 1 \mathrm{~m}^{2} \text { quadrat, visually } \\
\text { estimated) }\end{array}$ & $\%$ \\
\hline & Moss Cover & $\begin{array}{l}\text { Field Measured ( } 1 \mathrm{~m}^{2} \text { quadrat, visually } \\
\text { estimated) }\end{array}$ & $\%$ \\
\hline & Litter \& Duff Cover & $\begin{array}{l}\text { Field Measured ( } 1 \mathrm{~m}^{2} \text { quadrat, visually } \\
\text { estimated) }\end{array}$ & $\%$ \\
\hline & Litter \& Duff Depth & $\begin{array}{l}\text { Field Measured ( } 4 \text { measurements taken } \\
\text { and averaged } \\
\text { in each microsite plot) }\end{array}$ & $\mathrm{cm}$ \\
\hline
\end{tabular}

Tree vigor was qualitatively assessed for each juvenile species monitored. Vigor was categorized into three different classes: above average (AA), average (A), and low (L). These classes were determined by live crown ratio, early needle senescence, crown density, branchlet length, and needle chlorosis observed in each sampled species (Table 2). Live crown ratio was measured on juveniles large and old enough to exhibit more complex crown structure. Live crown ratio is the ratio of the crown length to total tree height or 
percentage of tree's total height that has foliage (U.S. Forest Service 2020; Deyoung 2016). Needle chlorosis assessment was based on foliar color where the proportion of yellowing needles was the basis for vigor classification. Low needle chlorosis indicates greater needle chlorophyll retained which in turn increases photosynthetic capacity (Grulke 2020; Nowak et. al. 1991). Crown density is the amount of crown branches, foliar retention and needle mass that blocks light visible through the crown (U.S Forest Service 2020). The different environmental variables associated with each vigor class for each species was analyzed to determine any patterns or trends. Hypotheses for the juvenile vigor assessment are as follows:

- Hypothesis 3: Juveniles classified in the AA vigor class will be present at sites with a lower canopy and tree density than juveniles classified in the A or L vigor classes.

- Hypothesis 4: Juveniles classified in the AA vigor class will present at sites with a higher TWI and lower HLI than sites juveniles classified in the A or L vigor classes.

Table 2. Qualitative variables measured during rapid vigor assessment of juvenile conifers.

\begin{tabular}{lcccc}
\hline \multicolumn{4}{c}{ Qualitative Vigor Classification } \\
\hline Vigor Qualitative Variable & Low (L) & Average (A) & $\begin{array}{c}\text { Above } \\
\text { Average (AA) }\end{array}$ & Reference \\
\hline Live Crown Ratio & $<0.2$ & $<0.4$ & $>=0.4$ & USFS (2020) \\
Crown Density & Qualitatively classified into each of the 3 classes & USFS (2020) \\
Early Needle Senescence & Severe & Mild & Not Present & Grulke (2020) \\
& Thinner & Intermediate & & \\
Branchlet Length & Branchlets & Length & Greater Length & Grulke (2020) \\
Needle Chlorosis \% & $>=15$ & $<15$ & 0 & Grulke (2020) \\
\hline
\end{tabular}




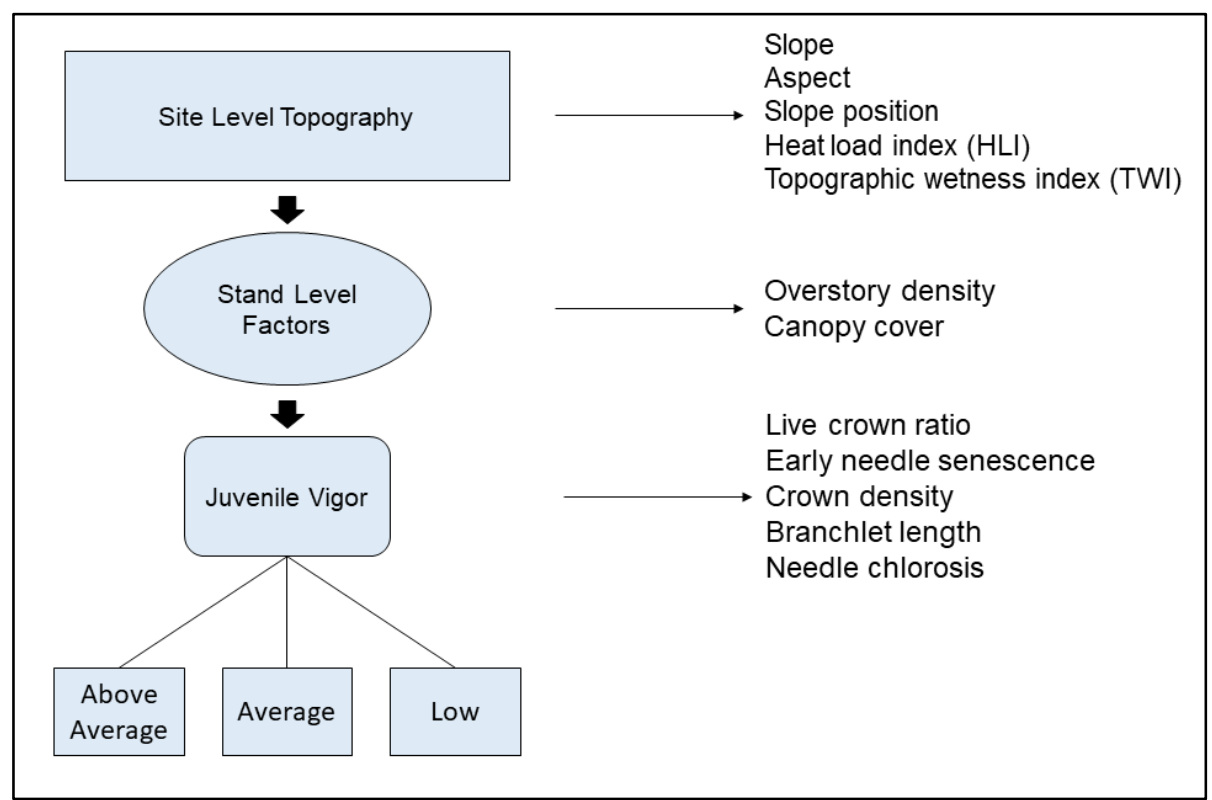

Figure 6. Conceptual model of juvenile vigor class assessment analysis.

\section{Statistical Analysis}

Non-parametric based tests were used in lieu of one-way ANOVA approaches because many of the results did not meet test assumptions for parametric approaches such as normality or equal variance. Wilcoxon rank-sum tests were used to determine significant differences among different microsite environmental variables measured in each paired microsite plot. Kruskal Wallis tests were used to test significant differences in different overstory density between sample units. A post-hoc Dunn's test was used determine significance differences between sample units. The relationship between juvenile conifer presence and microsite predictor variables was modeled using a boosted regression tree (BRT) approach. The BRT technique is a non-parametric regression method that combines classification and regression trees (CART) with a boosting algorithm, leveraging the advantages of CART models without losing predictive performance. Advantages of using 
CART-based approaches for ecological modeling include the ability to use predictor variables of different types and distributions and for accommodating missing data. Models were built using R Studio software version 1.2.5 (RStudio Team 2019). The BRT models were built using the 'gbm' package and its extensions (Ridgeway 2006; Elith et. al. 2008).

To ensure each model's accuracy, the presence (regeneration microsite plots) and absence (control microsite plots) data were partitioned with an 80-20 split, such that 80\% of the data was used to train each model and $20 \%$ of the data was used to test each model. Model validation was conducted using 3 metrics: percent deviation explained in independent (testing) data, percent deviation explained by cross-validation procedure, and area under the operating curve (AUC) averaged during cross-validation testing. A confusion matrix was also generated to assess each model's accuracy and to display any misclassification errors. Cohen's kappa statistic was also reported from each confusion matrix to compare the observed accuracy of each model with expected or random accuracy. This performance statistic was included because the model has a 50/50 chance of correctly classifying juvenile presence and additional metrics besides misclassification rate are necessary to assess a classification model's performance. The Kappa statistic essentially reports how much better the model is performing over a model that guesses at random based on frequency of each class.

Each model was fit using the gbm.step function to identify the optimal number of boosting trees. The optimal number of boosting trees was calculated using k-fold crossvalidation in the gbm.step function. The data was divided into 10 subsets in the k-fold cross validation where 1 subset was held out for validation and the other 9 subsets were used to 
train the model. The function then fit a model of increasing complexity, i.e., increasing number of nodes in trees, calculating the residual deviance at each step along the way. After each fold processed, the function calculated the average residual deviance and its standard error and then identified the optimal number of trees as that at which the deviance was minimized. Additional model parameters were also adjusted, these included tree complexity $=3$, learning rate $=0.005$ and bag fraction $=0.7$.

In order to eliminate non-informative variables, the models were simplified using the gbm.simplify function. This function dropped the least important predictor variable, then re-fitted the model and repeated the process. This process utilized a 10-fold crossvalidation procedure that progressively simplified the model at each fold and used the average cross-validation error to decide how many variables can be removed from the original model without losing predictive performance. Once the optimal number of predictor variables to drop was identified, the model was then fit again with the remaining predictor variables.

\section{Results}

Across the three study areas in Forest Park, 90 plots were established and monitored in this research. In the south management unit, 38 plots were established (18 TSHE plots and 20 THPL plots), which included 40 total juveniles monitored (6 seedlings and 34 saplings). In the north management unit, 40 plots were established (20 plots of each species), and a total of 44 juveniles were monitored (12 seedlings and 32 saplings). In the Burlington reference unit, 12 plots were established (6 of each species) which included 12 total juveniles ( 3 seedlings and 9 saplings). Juveniles were tracked and encountered more 
frequently in the reference and north units compared to the south unit (Table 3). Search encounter rate in the north unit for TSHE was 18.6 individuals per hour and 32.2 individuals per hour for THPL. Juveniles of both species were encountered least frequently in the south unit with an encounter rate for TSHE was 5 individuals per hour and 11.2 THPL individuals per hour.

Table 3. Juvenile search and encounter frequency metrics including mean species encountered per hour, total search time and total distance searched. Values in parentheses indicate the standard error.

\begin{tabular}{lrrrr}
\hline Unit & TSHE Per Hour & THPL Per Hour & Total Time (hr) & Total Distance (km) \\
\hline South & $5(1.5)$ & $11.2(3.3)$ & 12.7 & 16.6 \\
North & $18.6(4.1)$ & $32.2(4.8)$ & 14.9 & 18.2 \\
Burlington & $10.7(7.6)$ & $34.3(6.1)$ & 1.7 & 2.4 \\
\hline
\end{tabular}

The plots ranged in elevation from 260 to 980 feet and were established in representative aspects and slope positions. Both species sites were similar in topography ranging from 21-22 degrees in mean slope, 0.53-0.56 in mean heat load index and 2.9-3.1 in mean topographic wetness index (Table 4). Juveniles of each species were observed most frequently on NW, N and NE facing slopes (58\% of juveniles) and observed less frequently on SE, S and SW facing slopes (22\% of juveniles; Figure 7). Since, NW, N and NE facing slopes accounted for $51 \%$ of the study area, while SE, S and SW facing slopes accounted for $30 \%$ of the study area, this shows a habitat preference for NW, N, and NW facing slopes. 
Table 4. Summary statistics of topographic variables measured at each juvenile species' sites.

\begin{tabular}{llll}
\hline Topographic Variable & TSHE & THPL & Entire Park \\
\hline Elevation Range (Feet) & $330-951$ & $257-980$ & $36-1,127$ \\
Mean Slope (Degrees) & 21.8 & 21.2 & 24.1 \\
Slope Range (Degrees) & $4-33.5$ & $3-39$ & $0-81.4$ \\
Mean HLI & 0.53 & 0.56 & 0.5 \\
HLI Range & $0.12-1.05$ & $0.15-1$ & $0.01-1.06$ \\
Mean TWI & 2.89 & 3.05 & 3.02 \\
TWI Range & $0.01-8.7$ & $0.5-9$ & $0-18.4$ \\
\hline
\end{tabular}

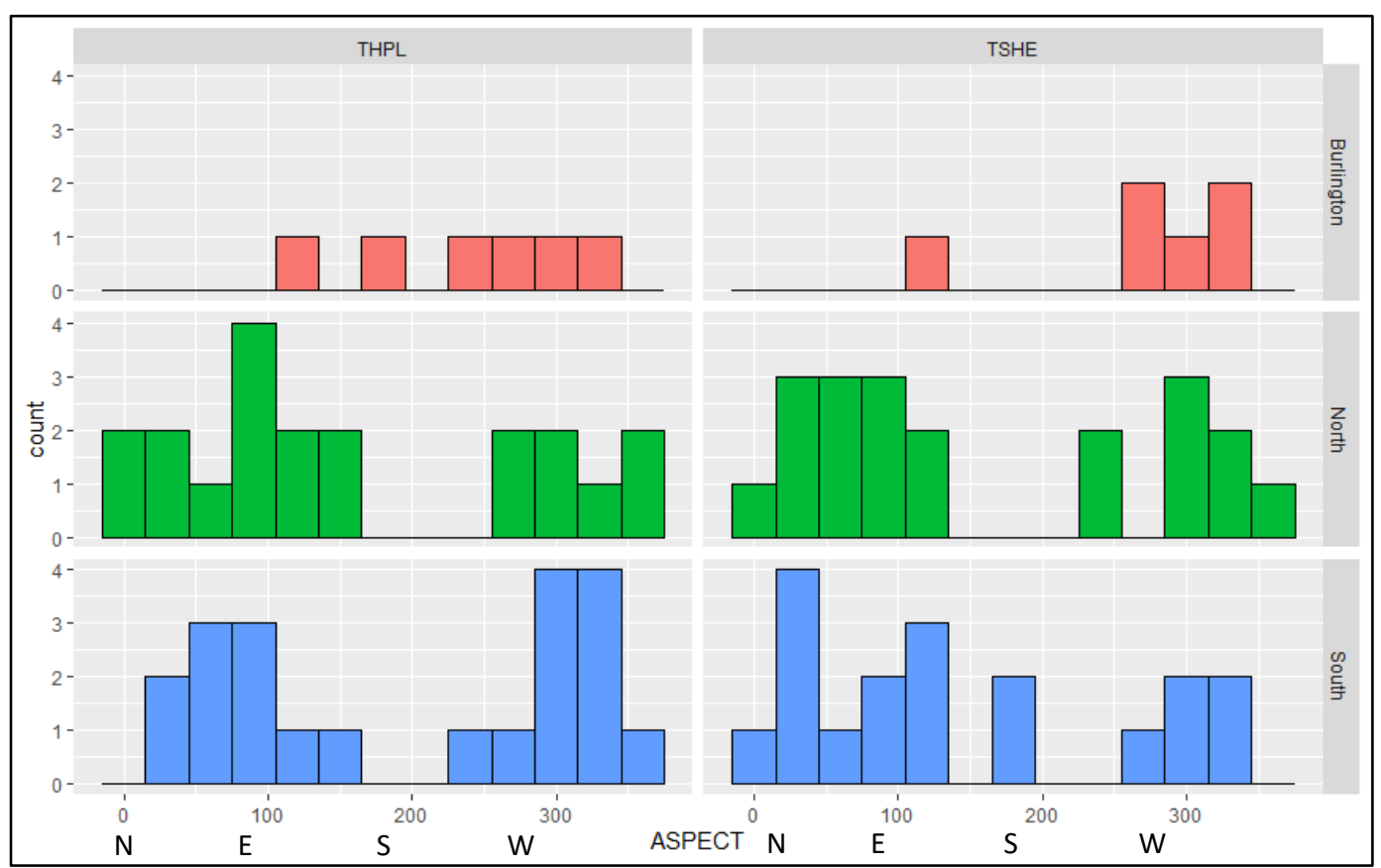

Figure 7. Distribution of aspect positions recorded for each species in each sample unit. 


\section{Vegetation Cover Effects on Juvenile Presence}

Vegetation Cover at TSHE Sites

Vegetation cover differed at regeneration and control microsite plots only in the fern categories. Fern cover was significantly lower in regeneration plots in all management units for TSHE (Figure 8). Mean fern cover ranged from 6 - 16\% in regeneration microsite plots and ranged from 35 - 65\% in corresponding control microsite plots (Table 5). Shrub cover ranged from $1-12 \%$ between microsite and control plots in all units but was not significantly different. Ivy was only observed in microsite plots located in the south management unit but was minimally present in both regeneration and control plot $(\sim 1 \%)$. Herbaceous cover was also negligible at TSHE sites ranging from $0-5 \%$ and not significantly different.

Vegetation Cover at THPL Sites

At THPL sites, vegetation cover differed at regeneration and control microsite plots in fern and shrub categories but not in every unit (Figure 9). Mean fern cover ranged from $9-21 \%$ at regeneration microsite plots and $26-72 \%$ at control microsite plots and was only significantly different in the north unit $(\mathrm{p}=0.0003$; Table 5). Shrub cover ranged from $3-19 \%$ at regeneration microsite plots and $13-32 \%$ at control microsite plots with shrub cover significantly lower in the south and Burlington units $(\mathrm{p}=0.05 ; \mathrm{p}=0.06$; Table 5). Ivy was mainly present in the south unit ranging from $4-7 \%$ at both regeneration and control microsite plots but was not significantly different. Herbaceous cover was minimally present at sites in each unit with the most herbaceous cover observed in south unit (Table 5), although not significantly different between regeneration and control microsite plots 


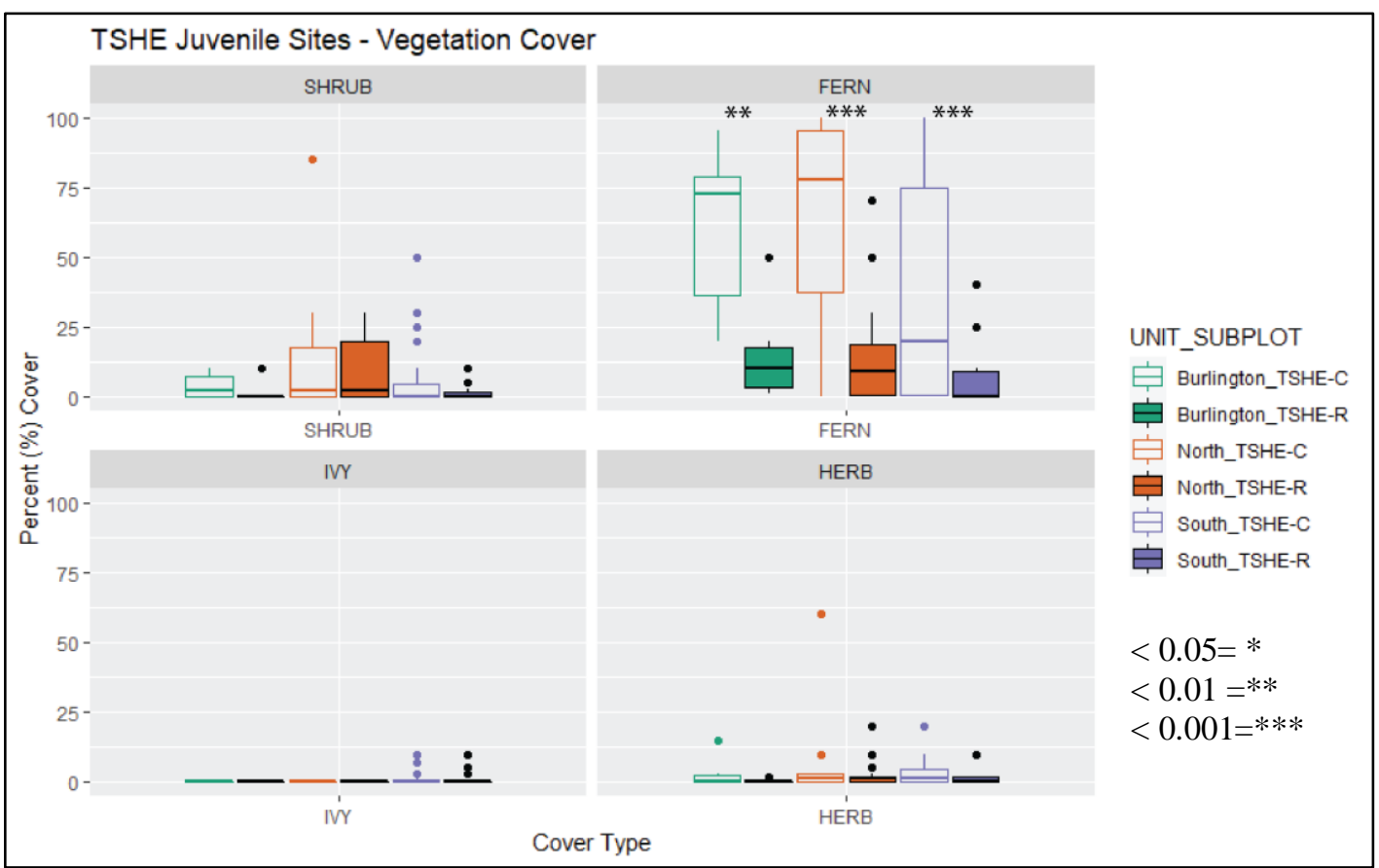

Figure 8. Distributions of vegetation cover percentages by category observed at TSHE juvenile sites. Boxplots with solid fill represent the seedling/sapling microsite plot $(\mathrm{R})$ and the outlined boxplots represent the control microsite plot $(\mathrm{C})$.

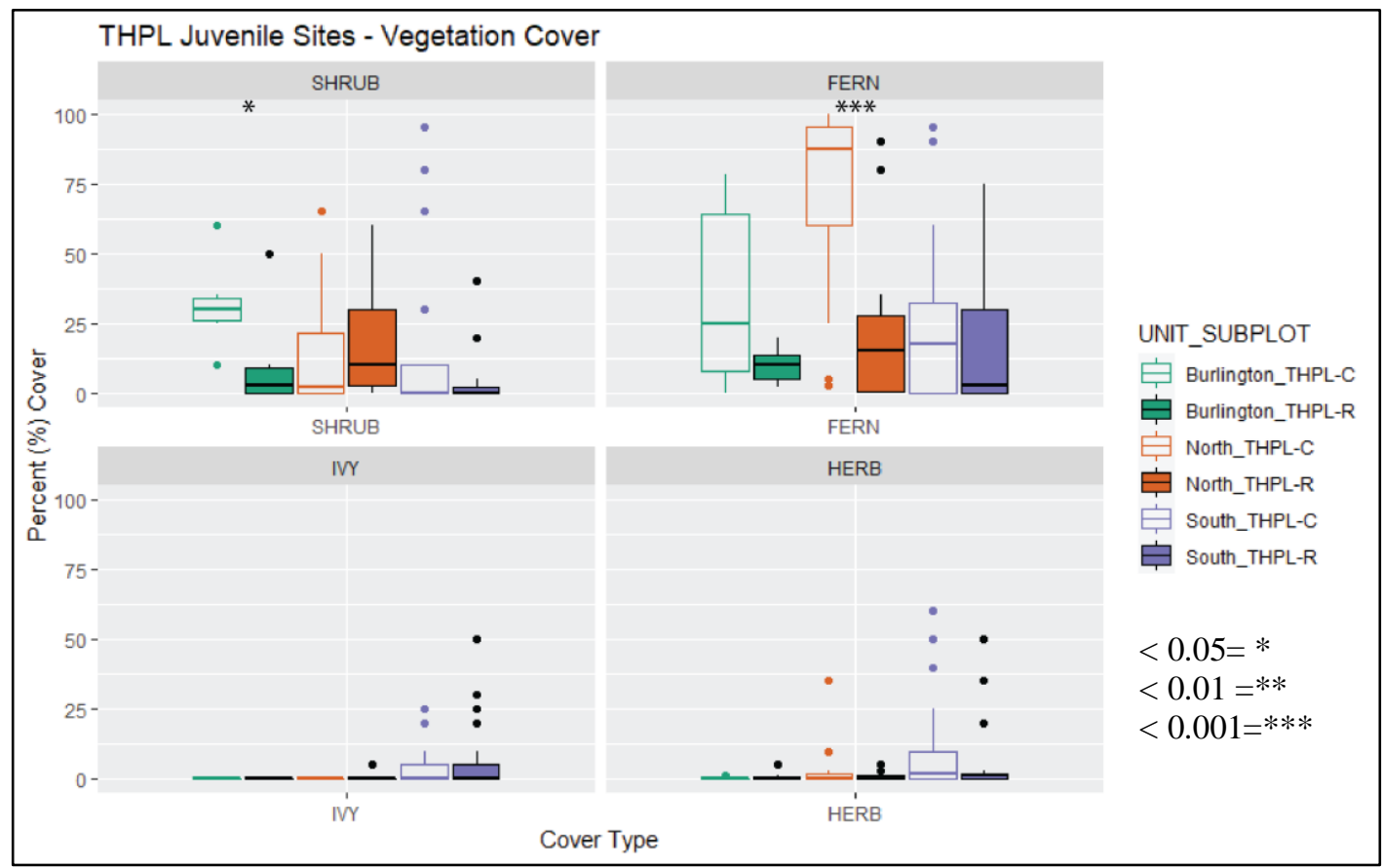

Figure 9. Distributions of vegetation cover percentages by category observed at THPL juvenile sites. Boxplots with solid fill represent the seedling/sapling microsite plot $(\mathrm{R})$ and the outlined boxplots represent the control microsite plot (C). 
Table 5. Mean vegetation percent cover for each vegetation cover group. Percent cover visually estimated in $1 \mathrm{~m}^{2}$ quadrat surrounding the seedling/sapling. Values in parentheses indicate the standard error.

\begin{tabular}{|c|c|c|c|c|c|c|c|}
\hline \multirow{2}{*}{$\begin{array}{c}\text { Sample } \\
\text { Unit }\end{array}$} & \multirow{2}{*}{$\begin{array}{l}\text { Cover } \\
\text { Type } \\
\end{array}$} & \multicolumn{2}{|c|}{ TSHE } & \multicolumn{4}{|c|}{ THPL } \\
\hline & & $\begin{array}{c}\text { Regeneration } \\
\text { Plots } \\
(\mathrm{n}=46)\end{array}$ & $\begin{array}{l}\text { Control } \\
\text { Plots } \\
(\mathrm{n}=48)\end{array}$ & $\mathrm{P}$-value & $\begin{array}{c}\text { Regeneration } \\
\text { Plots } \\
(\mathrm{n}=50)\end{array}$ & $\begin{array}{l}\text { Control } \\
\text { Plots } \\
(\mathrm{n}=50)\end{array}$ & P-value \\
\hline \multirow{4}{*}{ South Unit } & Herb & $1.4(0.6)$ & $3.9(1.3)$ & $.098^{1}$ & $5.7(2.5)$ & $10.2(3.4)$ & 0.13 \\
\hline & Shrub & $1.3(0.5)$ & $6.7(2.8)$ & $0.23^{1}$ & $3.1(1.7)$ & $13(5.5)$ & 0.06 \\
\hline & Ivy & $0.8(0.5)$ & $1.5(0.7)$ & 0.34 & $6.5(2.6)$ & $3.8(1.4)$ & 0.94 \\
\hline & Fern & $6(2.3)$ & $35.2(7.8)$ & $<0.0001^{1}$ & $15.6(4.3)$ & $26(6.4)$ & 0.29 \\
\hline \multirow{4}{*}{ North Unit } & Herb & $2.6(1.2)$ & $5.2(3)$ & $0.89^{2}$ & $1(0.4)$ & $2.8(1.8)$ & $0.65^{1}$ \\
\hline & Shrub & 8.9 (2.6) & $11.8(4.6)$ & $0.89^{2}$ & $19.4(4.6)$ & $14(4.4)$ & 0.24 \\
\hline & Ivy & $0(0)$ & $0(0)$ & NA & $0.3(0.3)$ & $0(0)$ & NA \\
\hline & Fern & $14.4(4.5)$ & $62.9(8.2)$ & $\mathrm{O.0003}^{2}$ & $21.4(5.8)$ & $72.9(7.1)$ & $<0.0001$ \\
\hline \multirow{5}{*}{$\begin{array}{l}\text { Burlington } \\
\text { Unit } \\
\text { (Reference) }\end{array}$} & Herb & $0.3(0.3)$ & $3.0(2.4)$ & $0.4^{2}$ & $1.0(0.8)$ & $0.2(0.2)$ & $0.5^{2}$ \\
\hline & Shrub & $1.7(1.7)$ & $3.7(1.8)$ & 0.78 & $10.8(8.0)$ & $31.7(6.7)$ & 0.05 \\
\hline & Ivy & $0(0)$ & $0(0)$ & NA & $0(0)$ & $0(0)$ & NA \\
\hline & Fern & $15.3(7.5)$ & 60.8 & 0.01 & $10(2.8)$ & 34.5 & 0.26 \\
\hline & & & (12.6) & & & $(14.0)$ & \\
\hline
\end{tabular}

${ }^{1}$ Indicates logarithmic transformation used in statistical analysis.

${ }^{2}$ Indicates a square root transformation used in statistical analysis.

\section{Forest Floor Substrate Effects on Juvenile Presence}

\section{Forest Floor Substrate Cover at TSHE Sites}

Coarse wood debris (CWD) was prevalent at TSHE regeneration microsite plots in every sample unit (Figure 10). About $84 \%$ of regenerating TSHE juveniles were found established on CWD. Mean CWD cover ranged from 23 - $53 \%$ at regeneration plots and $2-12 \%$ at control plots and was significantly higher in regeneration microsite plots at each unit — south ( $\mathrm{p}=0.008)$, north $(\mathrm{p}=<0.0001)$ and Burlington $(\mathrm{p}=0.05$; Table 6). Mean litter 
cover was significantly lower at regeneration microsite plots in the north and south units (Table 6). Litter cover ranged from $56-65 \%$ at regeneration microsite plots at all units while ranging from $74-92 \%$ in corresponding control microsite plots. Mean duff depth was significantly larger only in the south unit at around $\sim 10 \mathrm{~cm}$ in regeneration microsite plots (Table 6; $\mathrm{p}=0.001$ ). Litter depths ranged from $3-6 \mathrm{~cm}$ at both regeneration and control microsite plots in all units and were significantly different. Moss cover was significantly higher in regeneration microsite plots only in the north unit at $16 \%$ (Table 6; $\mathrm{p}=0.006$ ). Fine woody debris (FWD) was present at most site locations but not significantly different between regeneration and control microsites. Exposed mineral soil, rock duff substrates were exceedingly rare in each unit and observed least frequently amongst substrate categories.

\section{Forest Floor Substrate Cover at THPL Sites}

While multiple trends were observed between TSHE juveniles and forest floor substrate categories, THPL juveniles were not strongly associated with any substrate category (Figure 11). No substrate category was significantly different between regeneration and control microsite plots at THPL sites (Table 6). Only 17\% of regenerating THPL juveniles were found established on CWD, and mean CWD cover was typically low at regeneration microsite plots and not significantly different from control microsite plots in any unit (Table 6). Litter depths ranged from $5.5-7 \mathrm{~cm}$ at regeneration microsite plots and duff depths were negligible and ranged from $0.7-1.5 \mathrm{~cm}$. 


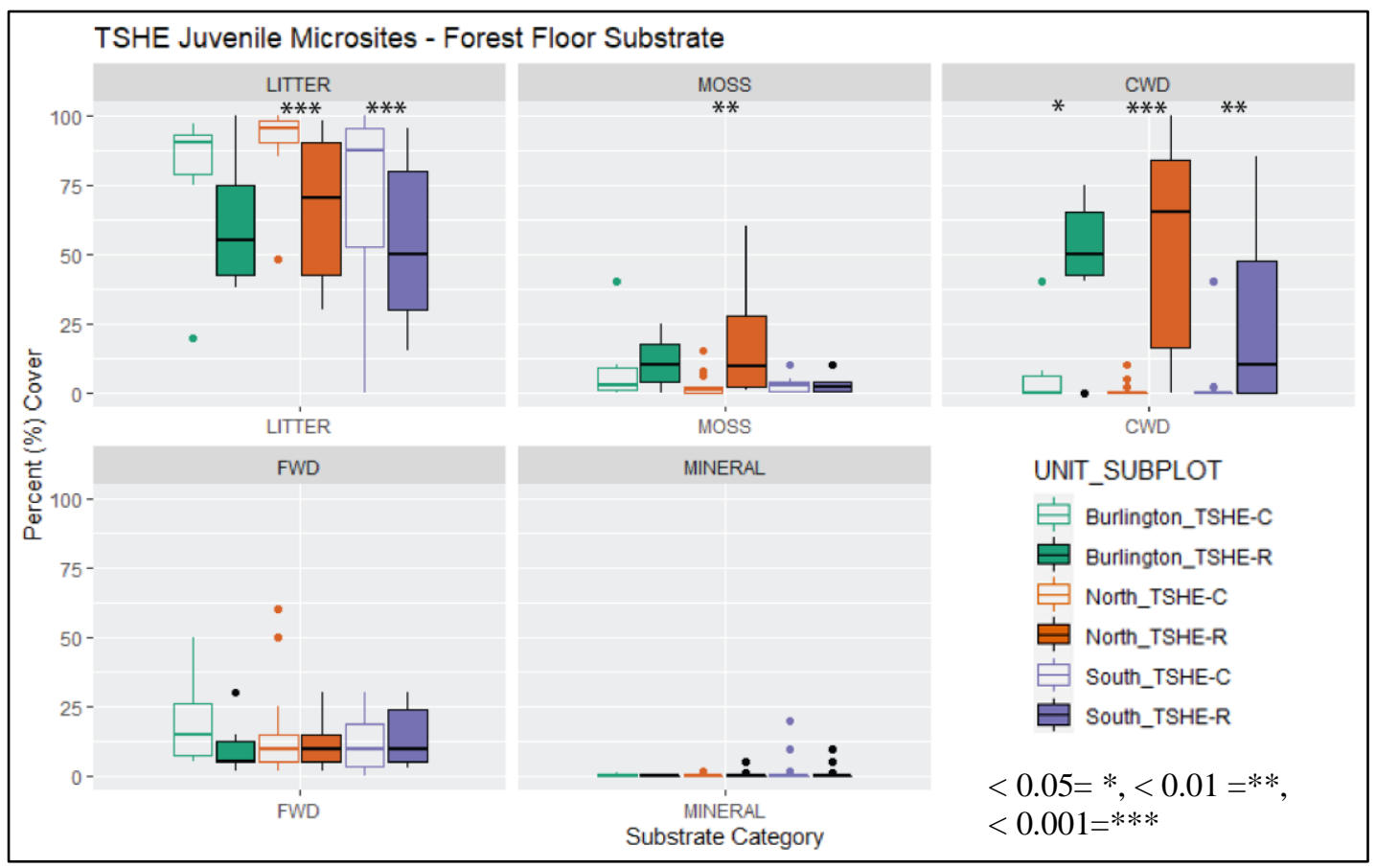

Figure 10. Distributions of vegetation cover percentages by category observed at TSHE juvenile sites. Boxplots with solid fill represent the seedling/sapling microsite plot (R) and the outlined boxplots represent the control microsite plot (C).

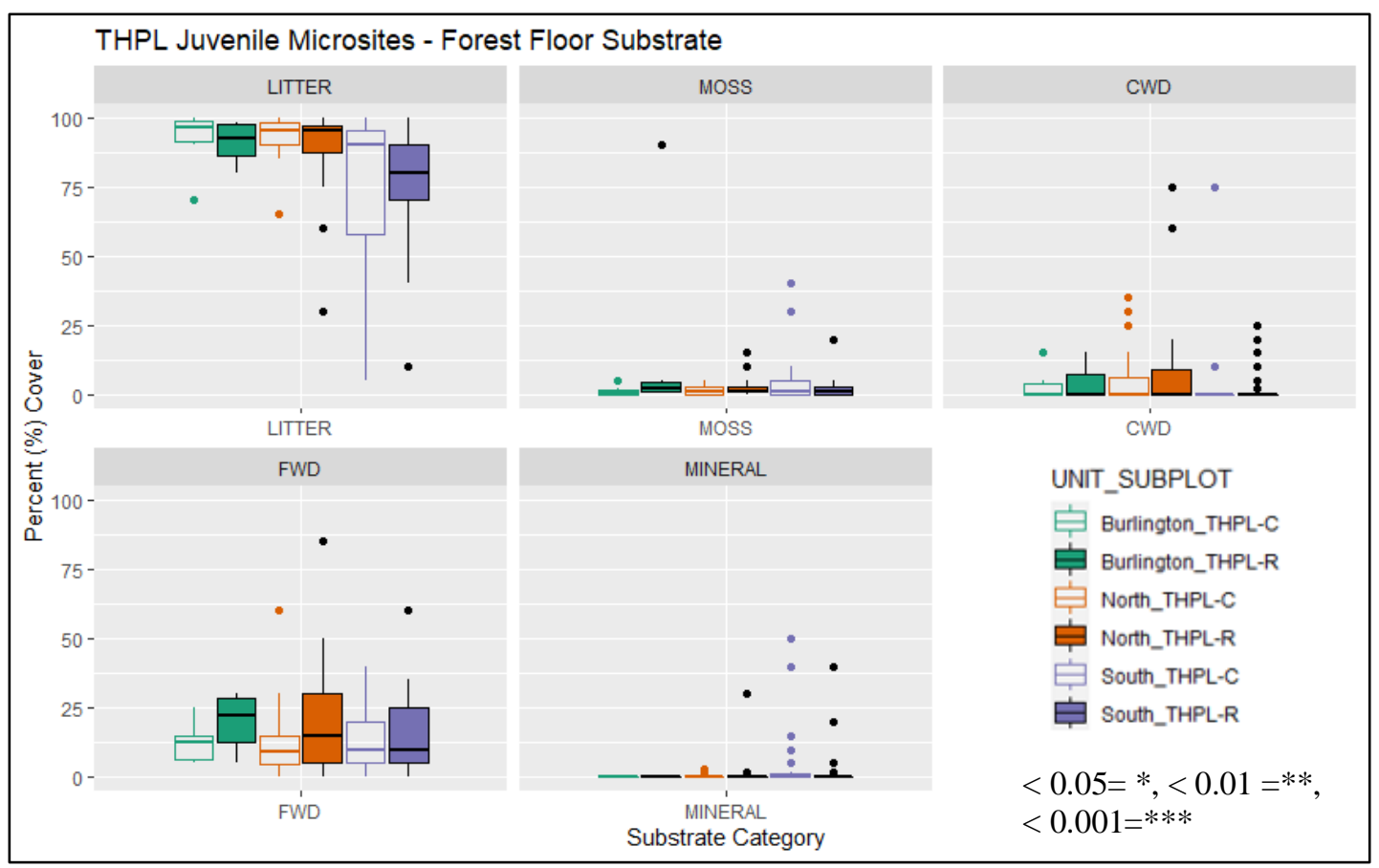

Figure 11. Distributions of vegetation cover percentages by category observed at THPL juvenile sites. Boxplots with solid fill represent the seedling/sapling microsite plot (R) and the outlined boxplots represent the control microsite plot (C). 
Table 6. Mean forest floor substrate variables measured at each target species site. Values in parentheses indicate the standard error. Litter and duff depth measured in $\mathrm{cm}$.

\begin{tabular}{|c|c|c|c|c|c|c|c|}
\hline \multirow[t]{2}{*}{ Unit } & \multirow{2}{*}{$\begin{array}{l}\text { Substrate } \\
\text { Category }\end{array}$} & \multicolumn{2}{|c|}{ TSHE } & \multicolumn{4}{|c|}{ THPL } \\
\hline & & $\begin{array}{l}\text { Regen } \\
\text { Plots } \\
(\mathrm{n}=45)\end{array}$ & $\begin{array}{c}\text { Control } \\
\text { Plots } \\
(\mathrm{n}=47)\end{array}$ & $\mathrm{P}$-value & $\begin{array}{l}\text { Regen } \\
\text { Plots } \\
(\mathrm{n}=49)\end{array}$ & $\begin{array}{c}\text { Control } \\
\text { Plots } \\
(\mathrm{n}=49)\end{array}$ & P-value \\
\hline \multirow{9}{*}{$\begin{array}{l}\text { South } \\
\text { Unit }\end{array}$} & Litter (\%) & $55.9(5.3)$ & $74.3(5.8)$ & .009 & $76.4(4.3)$ & $72.7(6.4)$ & 0.69 \\
\hline & Moss (\%) & $3.1(0.8)$ & $2.8(0.6)$ & 0.9 & $2.9(1.1)$ & $5(2)$ & 0.57 \\
\hline & CWD (\%) & $22.5(6.1)$ & $1.9(1.8)$ & 0.008 & $3.1(1.4)$ & $4.4(3.1)$ & 0.56 \\
\hline & FWD $(\%)$ & $14.5(2)$ & $10.8(1.9)$ & $0.12^{2}$ & $16.5(2.8)$ & $14.9(2.7)$ & 0.69 \\
\hline & Mineral (\%) & $0.7(0.5)$ & $1.5(1)$ & $0.67^{2}$ & $2.8(1.8)$ & $5.3(2.6)$ & 0.21 \\
\hline & Rock (\%) & $1.1(1.1)$ & $0.5(0.5)$ & na & $0(0)$ & $0(0)$ & na \\
\hline & Duff $(\%)$ & $4.8(2.3)$ & $3.9(3.6)$ & $0.24^{2}$ & $0.2(0.2)$ & $0(0)$ & na \\
\hline & Litter Depth & $5.5(0.6)$ & $4.7(0.6)$ & 0.3 & $5.7(0.8)$ & $5.2(1)$ & 0.34 \\
\hline & Duff Depth & $10(2.1)$ & $1(0.3)$ & .001 & $1.3(0.4)$ & $0.4(0.1)$ & $0.42^{1}$ \\
\hline \multirow{9}{*}{$\begin{array}{l}\text { North } \\
\text { Unit }\end{array}$} & Litter (\%) & $65.1(6.2)$ & $91.7(2.6)$ & 0.0003 & $88(4)$ & $92.6(1.8)$ & 0.59 \\
\hline & Moss (\%) & $16.3(4.1)$ & $2.4(0.9)$ & $.006^{1}$ & $2.9(0.9)$ & $1.7(0.4)$ & $0.4^{2}$ \\
\hline & CWD $(\%)$ & $52.8(8.7)$ & $0.9(0.5)$ & $<0.001$ & $9.6(4.9)$ & $6.35(2.5)$ & $0.78^{2}$ \\
\hline & FWD $(\%)$ & $12.4(2.2)$ & $14.8(3.4)$ & $0.72^{1}$ & $21(5)$ & $12.2(3)$ & $0.19^{2}$ \\
\hline & Mineral (\%) & $0.3(0.3)$ & $0.3(0.1)$ & na & $3.3(2.2)$ & $0.2(0.2)$ & na \\
\hline & Rock (\%) & $0.01(0.01)$ & $0(0)$ & na & $0(0)$ & $0(0)$ & na \\
\hline & Duff $(\%)$ & $1.7(0.8)$ & $0(0)$ & na & $0.1(0.1)$ & $0.05(0.05)$ & na \\
\hline & Litter Depth & $6.9(1.4)$ & $6.1(0.7)$ & 0.59 & $6.9(0.8)$ & 8.4 (1) & $0.26^{2}$ \\
\hline & Duff Depth & $6.7(4.9)$ & $1.6(0.6)$ & $0.19^{1}$ & $1.4(0.4)$ & $1.5(0.5)$ & 0.8 \\
\hline \multirow{9}{*}{$\begin{array}{l}\text { Ref. } \\
\text { Unit }\end{array}$} & Litter (\%) & $61.3(10)$ & 78 (11.9) & 0.38 & $87.5(3.2)$ & $88.8(6.6)$ & 0.87 \\
\hline & Moss (\%) & $11.8(4)$ & $9.5(6.3)$ & 0.52 & $24.3(22)$ & $1.8(1.2)$ & 0.38 \\
\hline & CWD $(\%)$ & $47.5(11)$ & $8(6.5)$ & 0.03 & $6.3(3.8)$ & $5(3.5)$ & 0.9 \\
\hline & FWD $(\%)$ & $10.3(4.3)$ & $20(7)$ & 0.24 & $15(4.6)$ & $11.3(4.7)$ & 0.65 \\
\hline & Mineral (\%) & $0(0)$ & $0.5(0.2)$ & na & $0(0)$ & $0(0)$ & na \\
\hline & Rock (\%) & $0(0)$ & $0(0)$ & na & $0(0)$ & $0(0)$ & na \\
\hline & Duff (\%) & $0.8(0.8)$ & $2(3)$ & na & $0(0)$ & $0(0)$ & na \\
\hline & Litter Depth & $4.8(1.4)$ & $3.4(0.8)$ & 0.43 & $5.5(0.9)$ & $3.5(1.1)$ & 0.38 \\
\hline & Duff Depth & $19.1(8.1)$ & $2.3(1.4)$ & 0.11 & $0.7(0.3)$ & $1.1(0.4)$ & 0.19 \\
\hline
\end{tabular}

${ }^{1}$ Indicates logarithmic transformation used in statistical analysis.

${ }^{2}$ Indicates a square root transformation used in statistical analysis. 


\section{Forest Structure and Composition}

\section{Forest Structure at TSHE Sites}

Mean total tree density was relatively similar at TSHE sites in each unit ranging from 213 - 270 trees/ha and not significantly different between sample units (Table 7; Figure 12). Bigleaf maple (ACMA) was more prevalent in the north (148 trees/ha) and south (102 trees/ha) units compared to the reference unit (33 trees/ha; $\mathrm{p}=0.05$; Table 7 ). The lowest density of Douglas-fir (PSME) was observed in the south unit (21 trees/ha). Western hemlock density ranged from 48 - 52 trees/ha with the highest density in the reference unit and the lowest density in the north unit. Western red cedar density ranged from 17 - 84 tree/ha with the lowest density observed in the south unit and the highest observed in the reference old-growth stand. More snags were observed in the reference unit than in the north or south units (Table 7). No significant difference was found between mean canopy cover density at TSHE microsite plot locations (97.2\%) and control plot locations (97.4\%; Table 8).

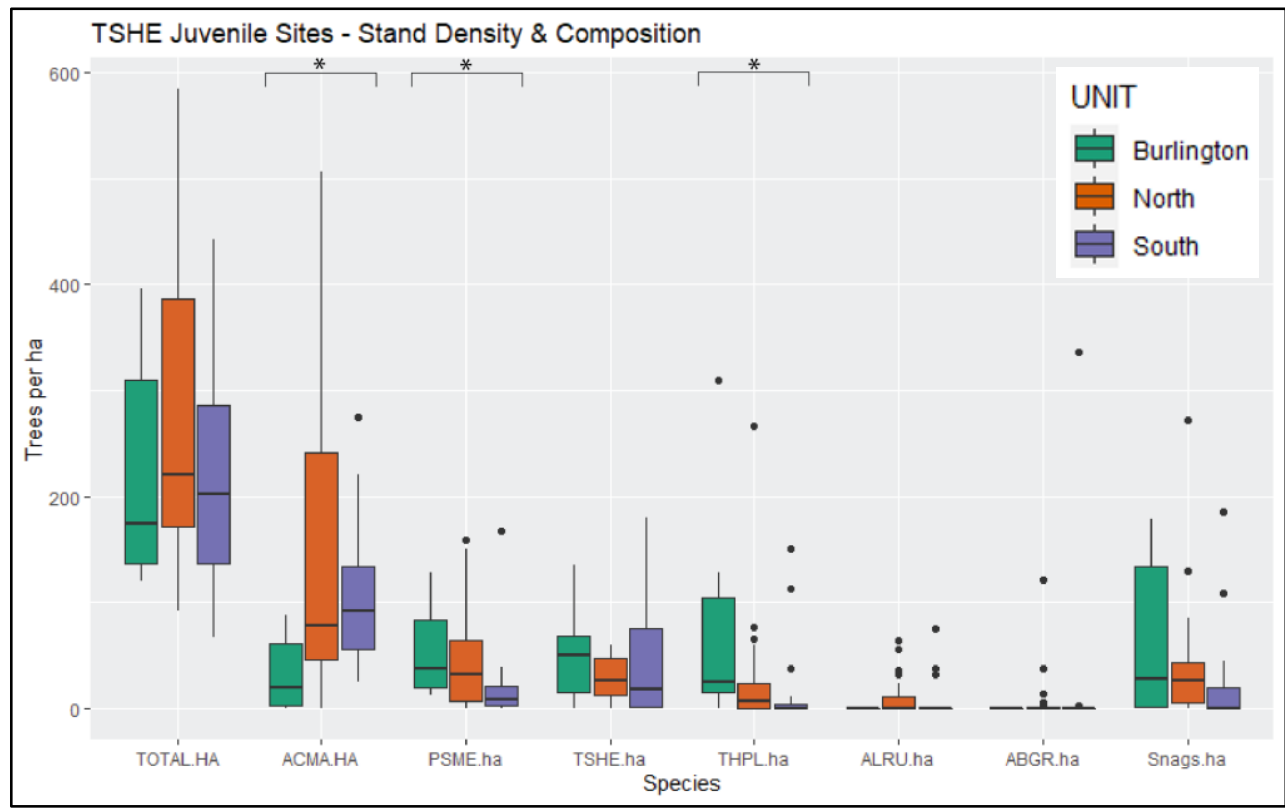

Figure 12. Stand density distributions by tree species in each sample unit observed at TSHE sites. Significance thresholds $<0.05=*,<0.01=* *,<0.001=* * *$. 


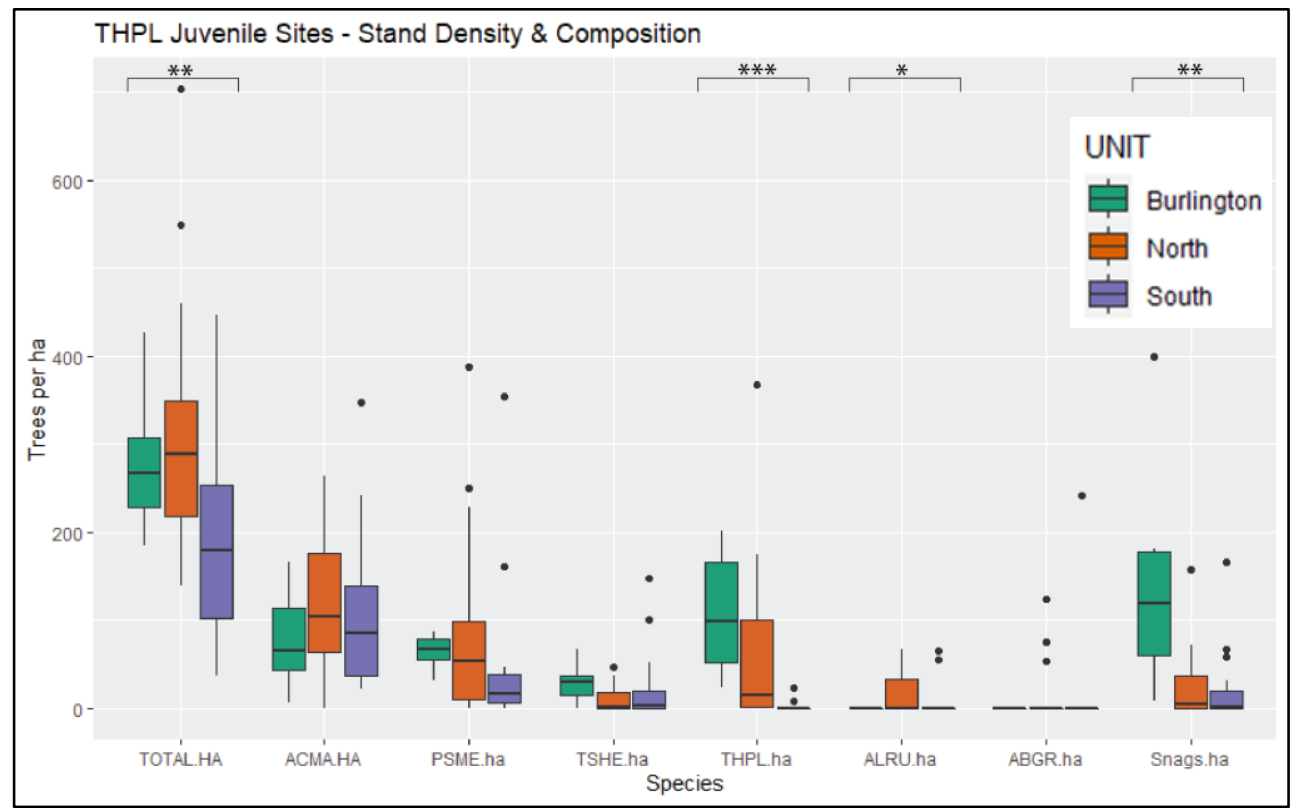

Figure 13. Stand density distributions by tree species in each sample unit observed at THPL sites. Significance thresholds $<0.05=*,<0.01=* *,<0.001=* * *$.

\section{Forest Structure at THPL Sites}

Mean total stand density was highest in the north unit (251 trees/ha) and lowest in the south unit (193 trees/ha) with the north and Burlington units significantly higher than the south unit ( $\mathrm{p}=0.006$; Table 7). Consistent with results from TSHE sites, bigleaf maple was more prevalent in the south (104 trees/ha) and north (116 trees/ha) units compared to the reference site (78 trees/ha) although not significantly different between units. Western red cedar density was lowest in the south unit ( 2 trees/ha) and highest in the reference unit (89 trees/ha). Douglas fir density was highest in the north unit (83 trees/ha) and lowest in the south unit (43 trees/ha). Snags were also more abundant in the reference unit than in the north of south units at THPL juvenile sites. While canopy cover density was slightly 
lower at regeneration sites than in the north and south units, the difference was not statistically significant (Table 8).

Table 7. Mean density (trees ha ${ }^{-1}$ ) of mature overstory trees present at TSHE and THPL juvenile sites. Standard error reported in parentheses.

\begin{tabular}{|c|c|c|c|c|c|}
\hline & $\begin{array}{l}\text { Overstory } \\
\text { Species }\end{array}$ & $\begin{array}{l}\text { South } \\
(n=18)\end{array}$ & $\begin{array}{l}\text { North } \\
(n=20)\end{array}$ & $\begin{array}{l}\text { Burlington } \\
\text { (Reference) } \\
(\mathrm{n}=12)\end{array}$ & P-Value \\
\hline \multirow{7}{*}{ TSHE } & Total & $212.7(24.6)^{1}$ & $271.3(32.3)^{1}$ & $224.3(48.7)^{1}$ & 0.49 \\
\hline & ACMA & $101.6(16.2)^{\mathrm{a}}$ & $147.9(33.8)^{\mathrm{a}}$ & $33.2(15.5)^{b}$ & 0.05 \\
\hline & PSME & $20.8(8.5)^{\mathrm{a}}$ & $46.8(11)^{b}$ & $54.9(19.2)^{\mathrm{b}}$ & 0.04 \\
\hline & TSHE & $47.9(13.3)$ & $28.11(4.7)$ & $52.2(20.2)$ & 0.68 \\
\hline & THPL & $16.8(9.6)^{\mathrm{a}}$ & $28.6(13.6)^{\mathrm{ab}}$ & $84(48.9)^{\mathrm{bc}}$ & 0.02 \\
\hline & ALRU & $7.7(4.5)$ & $11(4.5)$ & $0(0)$ & 0.33 \\
\hline & Snags & $24(10.8)$ & $43(14.1)$ & $66(34)$ & 0.07 \\
\hline \multirow{7}{*}{ THPL } & Total & $193.3(25.8)^{1 \mathrm{a}}$ & $310.2(30.8)^{1 b}$ & $280.2(35.1)^{1 \mathrm{~b}}$ & 0.006 \\
\hline & ACMA & $104.4(18.7)$ & $116.4(17.8)$ & $78.3(24.2)$ & 0.55 \\
\hline & PSME & $42.8(18.2)$ & 83.3 (22.9) & $64.7(8.3)$ & 0.06 \\
\hline & TSHE & $22(8.7)$ & $11.9(3.7)$ & $29.5(9.5)$ & 0.28 \\
\hline & THPL & $1.5(1.2)^{\mathrm{a}}$ & $66.6(20.7)^{\mathrm{b}}$ & $107.7(29.9)^{\mathrm{c}}$ & $<0.0001$ \\
\hline & ALRU & $0.9(4.1)^{\mathrm{a}}$ & $19.4(5.6)^{\mathrm{b}}$ & $0(0)$ & 0.02 \\
\hline & Snags & $20(8.9)^{\mathrm{a}}$ & $25.8(9.3)^{\mathrm{a}}$ & $147.6(57.1)^{\mathrm{b}}$ & 0.007 \\
\hline
\end{tabular}

P-values calculated by Kruskal-Wallis tests. Results with different superscript are significantly different from each other below 0.05 threshold determined by post hoc Dunn's test.

${ }^{1}$ Indicates square root transformation for statistical analysis

Table 8. Mean canopy cover density measured at each species regeneration $(\mathrm{R})$ microsite plots and control (C) microsite plots in each sample unit.

\begin{tabular}{lcclcll}
\hline \multicolumn{1}{c}{ Unit } & TSHE-R & TSHE-C & P-value & THPL-R & THPL-C & P-value \\
\hline South & $97.2(0.4)$ & $97.4(0.5)$ & 0.7 & $96.6(0.6)$ & $98(0.4)$ & 0.2 \\
North & $97.3(0.6)$ & $98.5(0.3)$ & 0.1 & $98.1(0.3)$ & $98.8(0.2)$ & 0.1 \\
Burlington & $98.2(0.6)$ & $98.4(0.7)$ & 0.1 & $98.6(0.3)$ & $98.1(0.5)$ & 0.6 \\
\hline
\end{tabular}




\section{Shade-Tolerant Conifer Prevalence in Overstory}

The stand level overstory results from both TSHE and THPL sites were further summarized to examine overall abundance of shade-tolerant species present in overstory and abundance of potential seed-bearing trees. Overall shade-tolerant conifer density was highest in the reference unit (142 trees/ha) and lower in both the south (63 trees/ha) and north $(78$ trees/ha) units $(\mathrm{p}=0.005)$. The density of TSHE seed trees (trees greater than 30 $\mathrm{cm}$ in diameter) was also highest in the reference unit (20 trees/ha) compared to the south and north units (Table 9). THPL seed tree density was lowest in the south unit but progressively increased in both north and reference units. THPL seed tree density was significantly different in each sample unit $(\mathrm{p}=0.001)$.

Table 9. Shade tolerant conifer overstory and seed tree density estimated from measurements taken at sampling locations where juveniles were found.

\begin{tabular}{lrrrr}
\hline & South & North & $\begin{array}{r}\text { Burlington } \\
\text { (Reference) }\end{array}$ & P-value \\
\hline Shade Tolerant Conifer Density & $63.3(12.9)^{\mathrm{a}}$ & $78.4(15.5)^{\mathrm{a}}$ & $141.5(25.8)^{\mathrm{b}}$ & $\mathbf{0 . 0 0 5}$ \\
TSHE Seed Trees (>30 cm DBH) & $15.4(3.5)$ & $15.5(2.8)$ & $20.4(6.8)$ & 0.6 \\
THPL Seed Trees (>30 cm DBH) & $2.3(1.2)^{\mathrm{a}}$ & $16.5(3.3)^{\mathrm{b}}$ & $24.9(4.4)^{\mathrm{c}}$ & $<\mathbf{0 . 0 0 0 1}$ \\
\hline
\end{tabular}

P-values calculated by Kruskal-Wallis tests. Results with different superscript are significantly different from each other below 0.05 threshold determined by post hoc Dunn's test.

\section{Juvenile Vigor}

Across all management units, juveniles of average and above average vigor outnumbered low vigor juveniles of both species (Figure 14). Western hemlock juvenile vigor class distribution was more varied by unit, while western red cedar vigor class distribution was more spatially even (Figure 14). Over all units, observed TSHE juveniles 
were assigned to the following classes: 17 - above average (AA), 13 - average (A) and 13 - low average (L). Observed THPL juveniles were assessed as follows: 17 - AA, 23 - A, and 7 - L. Fewer low vigor juveniles were observed compared to the A and AA classes for both species. Mean HLI and TWI observed for different vigor classes of THPL juveniles was also not significantly different. Heat load index (HLI), and topographic wetness index (TWI) did not differ significantly across vigor classes of both species (Table 10). Mean stand density was significantly different among vigor classes only for THPL juveniles $(\mathrm{P}=0.01 ;$ Table 10$)$.

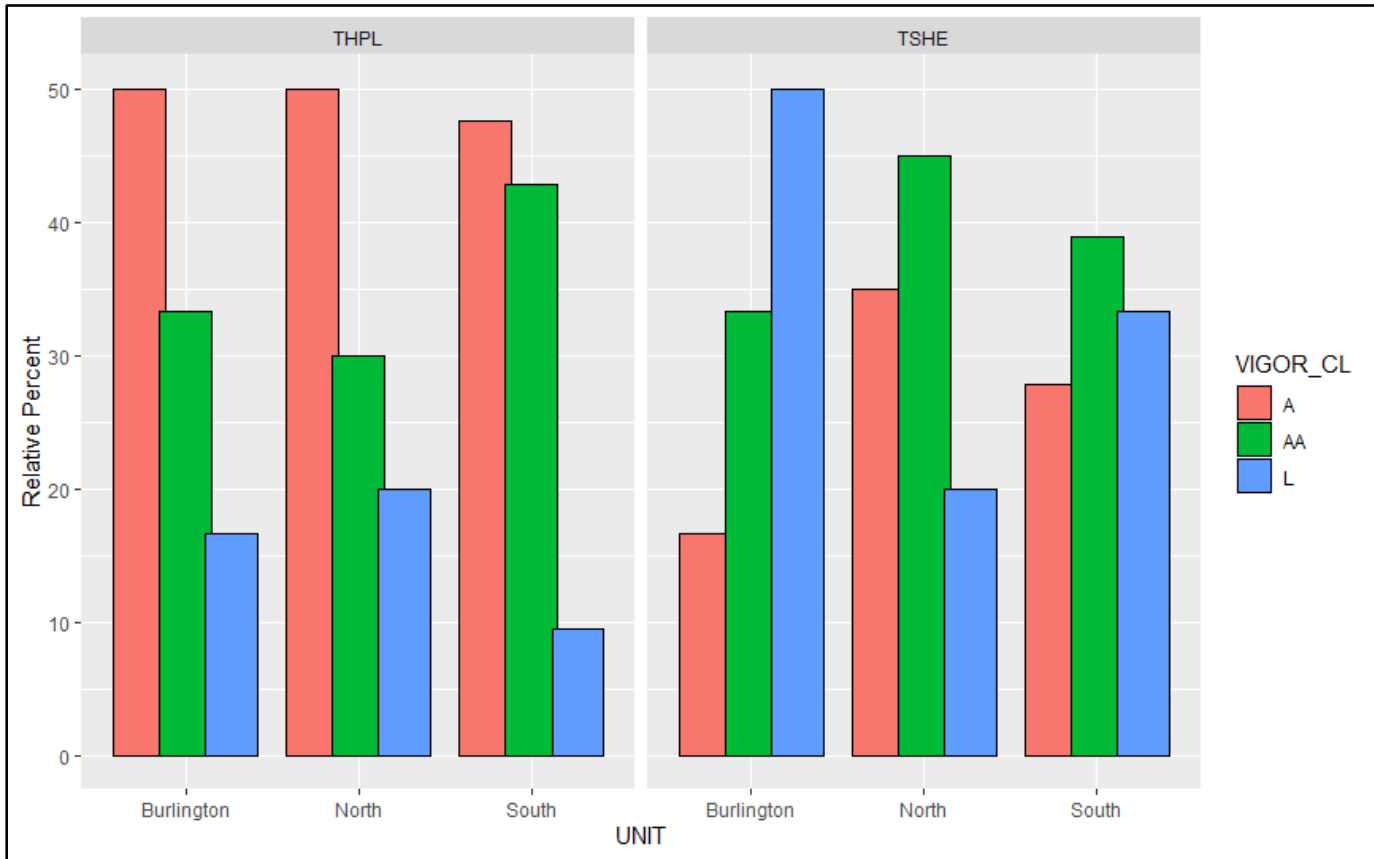

Figure 14. Relative percentages of observed vigor class by species and sample unit.

Table 10. Mean stand level variables assessed for each juvenile species' vigor classes. Vigor class codes: $\mathrm{AA}=$ above average vigor, $\mathrm{A}=$ average vigor and $\mathrm{L}=$ low vigor.

\begin{tabular}{lrrrrrrrr}
\hline \multirow{2}{*}{ Stand Variable } & \multicolumn{4}{c}{ TSHE } & \multicolumn{3}{c}{ THPL } \\
& $\mathrm{L}$ & \multicolumn{1}{c}{ A } & AA & P-value & L & A & AA & P-value \\
& $(\mathrm{n}=13)$ & $(\mathrm{n}=15)$ & $(\mathrm{n}=21)$ & & $(\mathrm{n}=7)$ & $(\mathrm{n}=23)$ & $(\mathrm{n}=17)$ & \\
\hline HLI & 0.56 & 0.54 & 0.53 & 0.83 & 0.53 & 0.58 & 0.66 & 0.45 \\
TWI & 2.6 & 2.7 & 3.02 & 0.84 & 2.9 & 3.3 & 2.7 & 0.47 \\
Trees ha $^{-1}$ & 246.6 & 256.9 & 235.23 & 0.53 & $\mathbf{2 8 8 . 6}$ & $\mathbf{2 9 0 . 4}$ & $\mathbf{1 9 0 . 9}$ & $\mathbf{0 . 0 1}$ \\
Canopy Cover $(\%)^{9}$ & 97.8 & 97.6 & 95.8 & 0.3 & 98.3 & 97.9 & 96.5 & 0.18 \\
\hline
\end{tabular}




\section{Predictive Models}

A boosted regression tree classification model was built to predict presence of each target species using microsite environmental variables. These predictor variables included forest floor substrate and vegetation cover categories measured at each species regeneration and control microsite plots. Both models performed moderately well on independent testing data and after cross-validation. The simplified TSHE model was fitted with 350 trees and the simplified THPL model was fitted with 250 trees. The optimal number of trees to use in each model was based on the cross-validation results. Correlation between environmental variables for both species was assessed using Pearson's correlation coefficients (r; Figure 15; Figure 16). CWD and moss cover were the most positively correlated of the TSHE environmental predictor variables $(r=0.54)$, while CWD and litter were the most negatively correlated at TSHE sites $(r=-0.5)$. Other notable correlations include CWD and fern at TSHE sites $(r=-0.4)$. At THPL sites, the largest correlation was observed between litter and mineral cover $(\mathrm{r}=-0.66)$, while herb and litter were also negatively correlated $(\mathrm{r}=-0.47)$. No environmental predictor variables were initially dropped in first BRT models. The gbm.simplify function was used to determine which predictor variables to drop based on their relative contributions to the models. Five predictor variables were dropped in the TSHE model: rock, duff, ivy, mineral and herb. Seven predictor variables were also dropped in the THPL model: CWD, litter, moss, rock, duff, ivy, and mineral. 
The most important predictors of juvenile TSHE presence were CWD and Fern cover (Table 11; Figure 17). CWD contributed most to the model at $51 \%$ and had a positive effect on the probability of TSHE juvenile presence. Fern cover contributed $23 \%$ to the model and had negative effect on the probability of TSHE presence. Shrub, litter, FWD and moss cover all had negative effects, but each contributed less than 10\%. Fern cover was the most important predictor variable in the THPL model (Table 11; Figure 18), contributing $43 \%$ to the model and had a negative effect on the probability of THPL presence, followed by shrub and herb cover. FWD had a small positive effect on the presence of THPL juveniles, contributing $\sim 5 \%$.

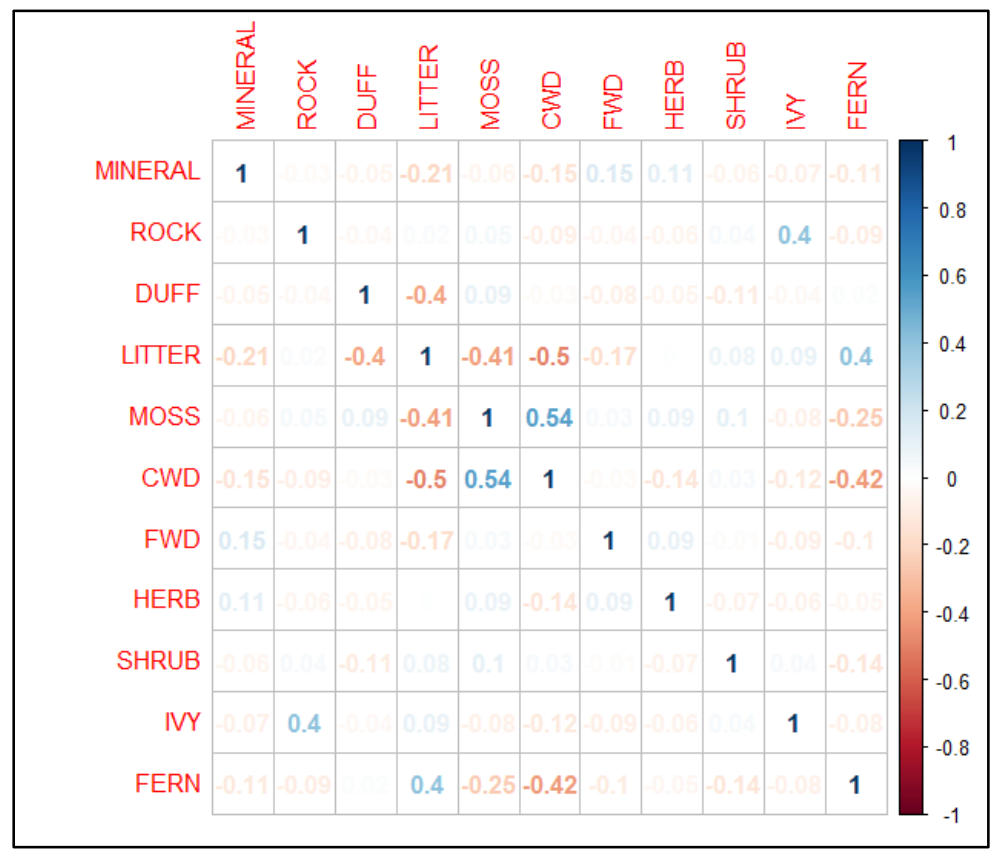

Figure 15. Correlation coefficient matrix containing Pearson correlation coefficients for all microsite environmental predictor variables used in the TSHE boosted regression tree model. 


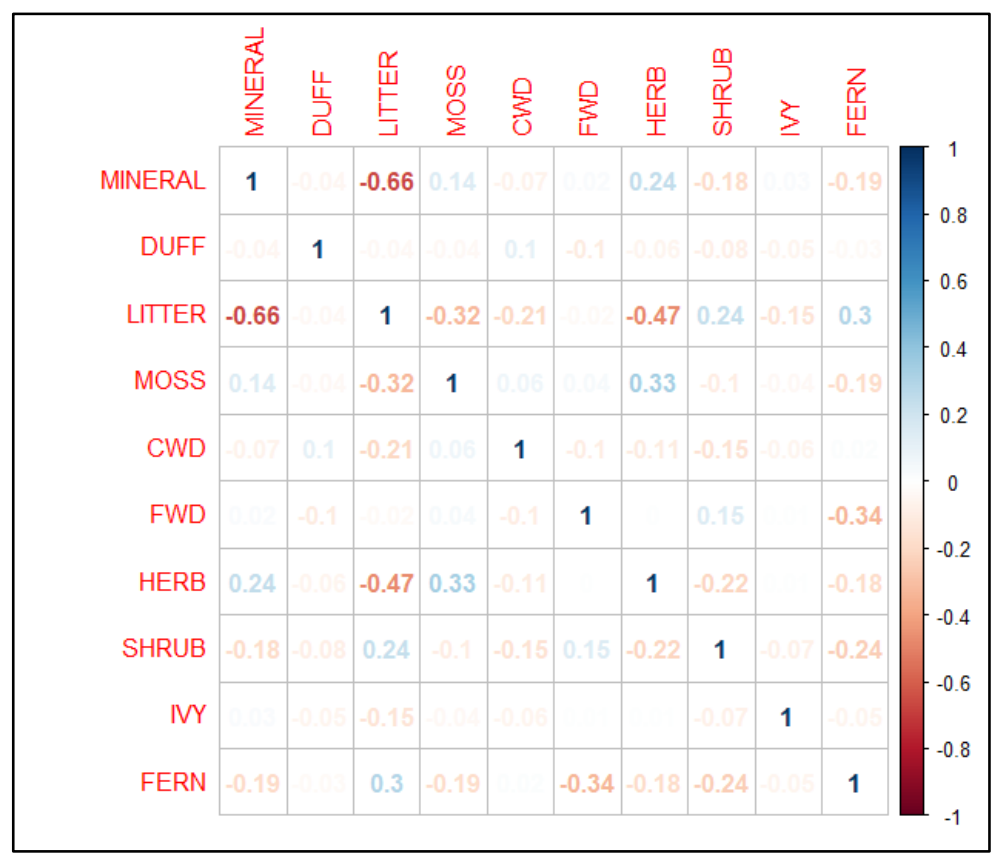

Figure 16. Correlation coefficient matrix containing Pearson correlation coefficients for all microsite environmental predictor variables used in the THPL boosted regression tree model.

The simplified BRT models identified the most important pair-wise interactions for both species, and pairs included the most influential predictor for each model (Figure 19). For the TSHE model, the most important pair-wise interaction was between CWD and fern cover which produced an interaction size value of 4.5. CWD and fern cover were negatively correlated, such that higher CWD cover increased the probability of TSHE presence while higher fern cover decreased the probability of TSHE presence. The next most important pair-wise interaction identified in the TSHE model was between fern and shrub cover, which produced an interaction size value of 1.8 .

For the THPL model, the most important pair-wise interaction identified was between fern and shrub cover, which produced an interaction size value of 14 . Higher cover of both variables decreased the probability of THPL juvenile presence. Fern and herb cover were the next highest interaction with an interaction size of 5.1 (Table 11). 
Table 11. Microsite environmental predictor variable influence and ranking for each species model.

\begin{tabular}{lclll}
\hline Model & Species & Predictor & Contribution (\%) & Effect \\
\hline & & CWD & 50.6 & + \\
& & Fern & 22.9 & - \\
& Western & Shrub & 10.3 & - \\
& hemlock & Litter & 6.7 & - \\
Microsite & (TSHE) & FWD & 5.7 & - \\
Presence/Absence & & Moss & 3.8 & - \\
& & & & \\
& Western red & Fern & 42.9 & - \\
& cedar & Shrub & 34.6 & - \\
& (THPL) & Herb & 17.2 & - \\
& & FWD & 5.3 & + \\
\hline
\end{tabular}

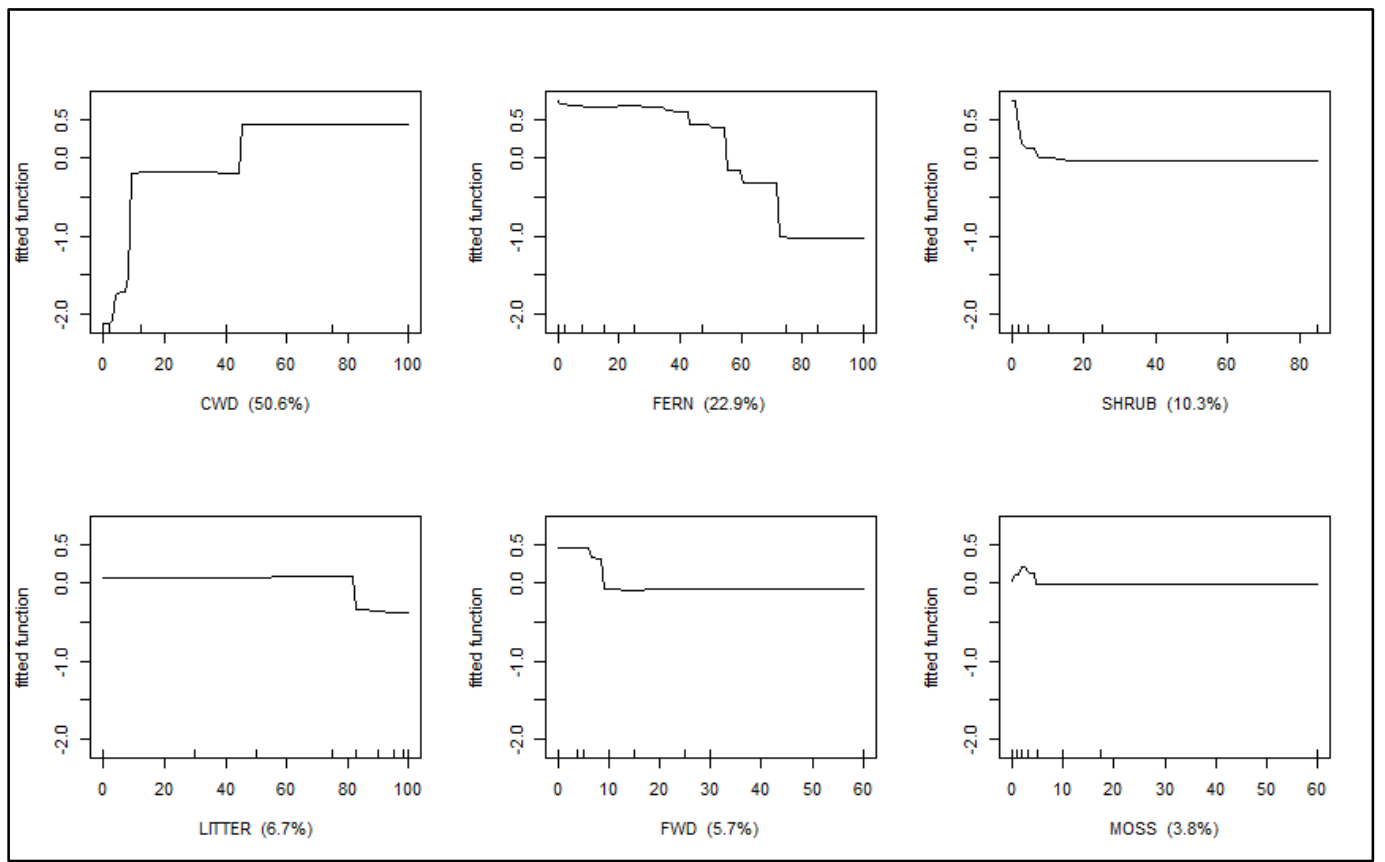

Figure 17. Partial dependency plots of probability of TSHE presence based on microsite predictor variables. Positive values on Y-axis are associated with higher probability of juvenile presence. 


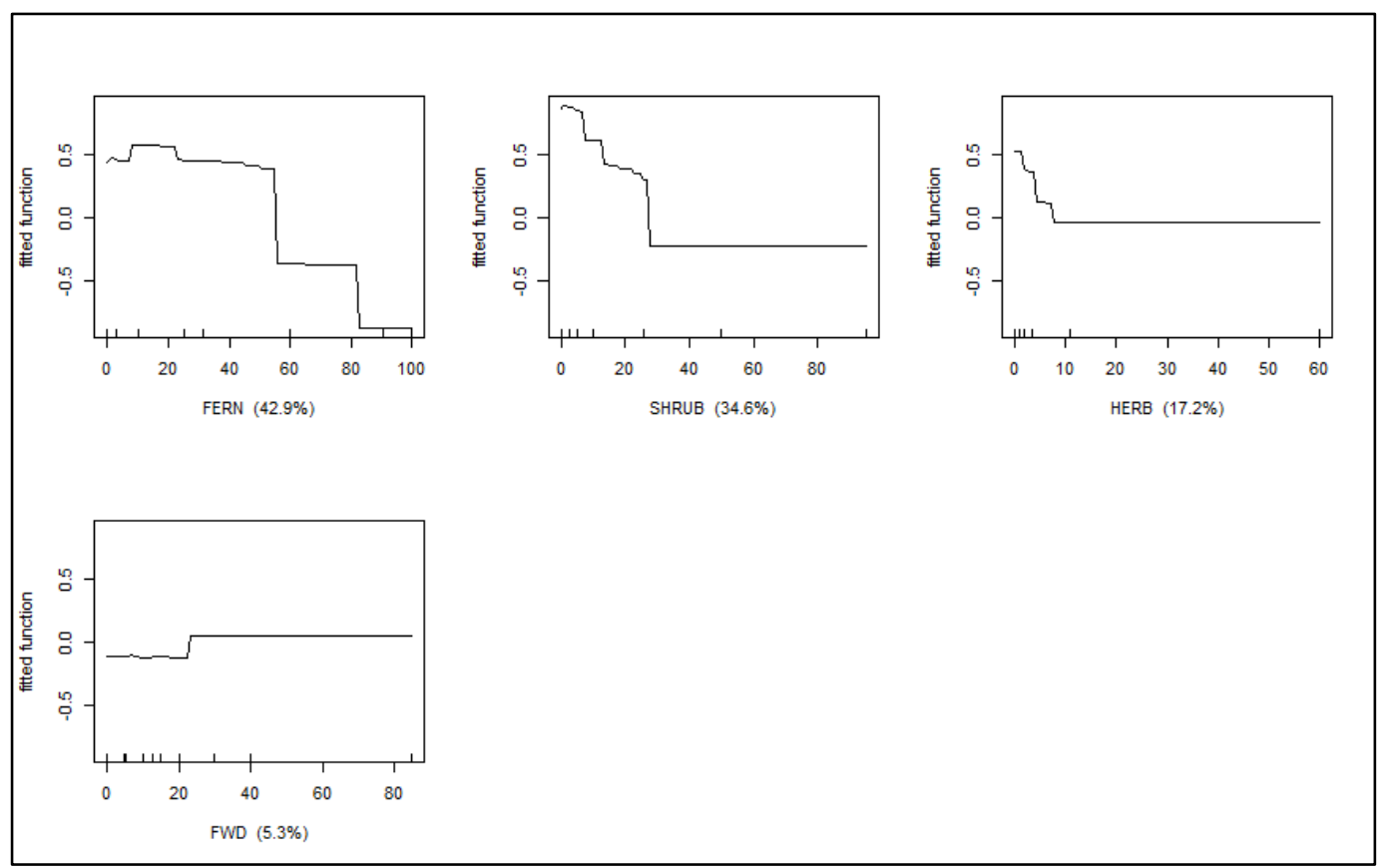

Figure 18. Partial dependency plots of probability of TSHE presence based on microsite predictor variables. Positive values on Y-axis are associated with higher probability of juvenile presence.

The TSHE BRT model performed better overall than the THPL model based on confusion matrix results (Table 12). The TSHE model deviance explained ranged from $33 \%-17 \%$ with the highest reported from the cross-validation procedure. The TSHE model performed well on independent testing data with a 0.73 AUC and $33 \%$ of deviance explained. The overall accuracy of the TSHE BRT model was 83\%, including a misclassification rate of $17 \%$ based on the confusion matrix created from the model's predicted classification of independent testing data. The TSHE model produced a 0.67 Kappa statistic. In contrast, the THPL model explained a lower proportion of deviance, ranging from $11-18 \%$ (Table 12). The highest deviance explained was reported from the fit model with independent testing data. The AUC values reported from the cross-validation procedure and independent testing data were both around 0.72 . The overall accuracy of the 
THPL model was $72 \%$ with a $28 \%$ misclassification rate. The THPL model produced a

Kappa statistic of 0.44 . Model accuracy was based on the confusion matrix created from

the model's predicted classification of independent testing data.

Table 12. Summary of evaluation metrics for both juvenile conifer species BRT model. AUC and \% deviance explained for 10-fold cross validation and independent testing data.

\begin{tabular}{llllllll}
\hline \multirow{2}{*}{ Model } & \multicolumn{2}{c}{ Cross-validation } & \multicolumn{2}{c}{ Independent } & \multicolumn{3}{c}{ Confusion Matrix } \\
\cline { 2 - 8 } & AUC & $\begin{array}{l}\text { \% Deviance } \\
\text { Explained }\end{array}$ & AUC & $\begin{array}{l}\text { \% Deviance } \\
\text { Explained }\end{array}$ & $\begin{array}{l}\text { Misclassification } \\
\text { Rate (\%) }\end{array}$ & $\begin{array}{l}\text { Overall } \\
\text { Accuracy (\%) }\end{array}$ & $\begin{array}{l}\text { Kappa } \\
\text { Statistic }\end{array}$ \\
\hline TSHE & 0.89 & 36.1 & 0.73 & 32.5 & 16.7 & 83.3 & 0.67 \\
THPL & 0.71 & 11.2 & 0.72 & 18.6 & 27.8 & 72.2 & 0.44 \\
\hline
\end{tabular}
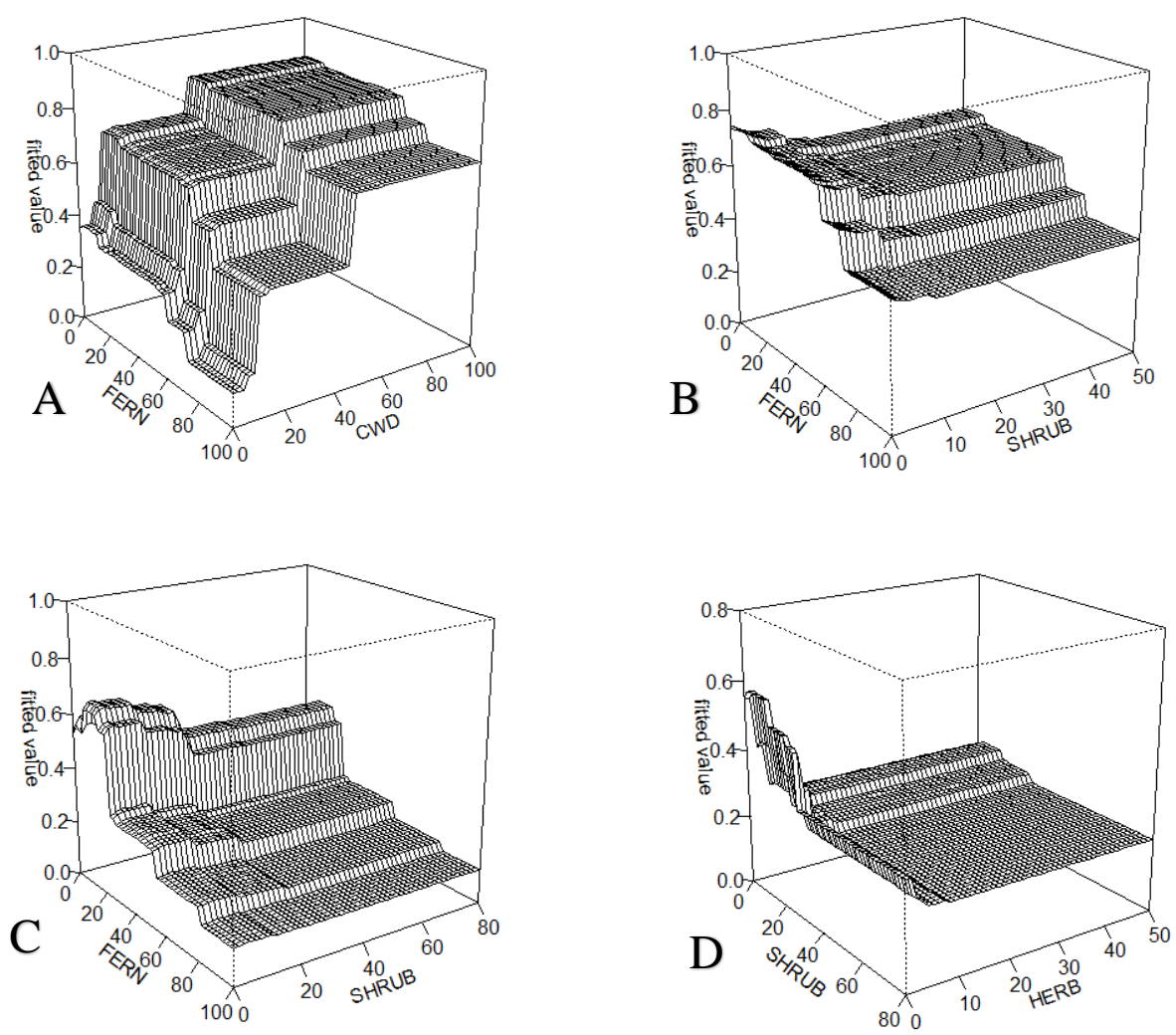

Figure 19. Three-dimensional partial dependence plots displaying the strongest interactions between predictor variables in each species model. These include fern and CWD cover (A) and fern and shrub cover (B) in the TSHE model. Also includes fern and shrub cover (C) and shrub and herb cover (D) in the THPL model. 


\section{Discussion}

Microsite Level Factors - Vegetation Cover

A study hypothesis was that regeneration microsite would differ from control microsites in total vegetation cover. The results of this study suggest that the successful establishment of both juvenile conifer species is sensitive to competitive dynamics occurring within understory plant communities. This was most evident in the analysis of the regeneration microsite and control microsite plot level variables. Juveniles of both species were consistently observed in microsite locations lacking heavy shrub and fern cover. Furthermore, fern and shrub cover were much denser away from juvenile conifers, i.e., in the control microsite plots (Figures 8; Figure 9). Shrub cover did not differ significantly between controls plots of TSHE species but was typically more abundant at control plots of THPL juveniles. Shrub cover was identified as an important variable in predicting presence of each species but not to the same magnitude as fern cover (Table 11). Understory vegetation can limit establishment of subordinate conifers due to competition for soil moisture, light, soil nutrients, and growing space (Balandier et al. 2006; Messier 1993; Beach and Halpern 2001). Other mechanisms in which dense understory vegetation inhibits tree regeneration include allelopathy, physical impediments of seedling germination and establishment and other indirect effects e.g., increased herbivory, increased presence of seed/seedling predators (Royo \& Carson 2006). Most understory species observed in regeneration sites were native species, but invasive species such as English ivy are a large concern for park stakeholders. 
English ivy was only observed in plots established in the south management unit. However, the presence of ivy was very negligible in both the regeneration plots and control plots. The ivy invasion is most prevalent in the south unit and has been the focus of restoration and management activities in the park for many decades (City of Portland 1995). The impacts of ivy on seedling establishment and growth were not specifically examined in this study. However, the results of this study suggest that understory competition is a significant barrier to seedling establishment. English ivy grows in thick dense mats and has observed to exclude native understory plants (Copp 2014). Increased ivy presence could limit the available microsites required for conifer seedling establishment. Conversely, other studies in other PNW urban forests concluded that establishment, germination, and survival of juvenile TSHE and THPL was limited by scarce coarse wood debris presence, not competition from English ivy (Ettinger et al. 2017).

Microsite Level Factors - Substrate Cover

Western hemlock juveniles were strongly, positively associated with the presence of CWD. These results were not surprising as the relationship between western hemlock regeneration occurring on decayed logs has been well documented (Christy \& Mack 1984; Harmon \& Franklin 1989; Schrader 1998). CWD serves as a safe site where TSHE seedlings can establish and grow with relatively little competition from ferns, shrubs, mosses, and herbs. CWD cover was negatively correlated with both fern and litter cover further displaying the facilitating role that downed logs provide on the forest floor surface. These results are consistent with other studies that identified a lack of CWD or nurse logs 
as an important limiting factor to western hemlock establishment and survival in areas where seed source was present (Harmon and Franklin 1989; Ettinger et al. 2017). The strong pattern of TSHE establishment on CWD in this study further supports the assertion that understory vegetation competition is a critical factor inhibiting seedling establishment and recruitment in Forest Park. Juveniles were established more frequently on partially decomposed logs than sound logs. This pattern has been observed in other studies as moderately decomposed logs still maintain ability to shed litter and provide safe site from vegetation yet provide a substrate for seeds to lodge (Christy \& Mack 1984). THPL juveniles were also found established on CWD (17\% of samples) but not to the same degree as TSHE juveniles (84\%).

Litter cover was significantly lower at regeneration sites for in the north and south units for TSHE juveniles. Litter depth and cover can affect microsite conditions and inhibit seedling emergence and establishment by reducing water availability and providing a barrier between seed and mineral soil (Caccia \& Ballaré 1998; Kostel-Hughes et al. 2005). Litter depth was not significantly different in regeneration versus control microsite plots for either species management units. Overall, the accumulation of litter on the forest floor did not appear to be a significant barrier to seedling establishment. Duff cover was generally negligible at all plots and occasionally present at TSHE sites with CWD presence. Duff depth was significantly greater at TSHE sites in all units again due to the presence of CWD. Over time, CWD decomposes and produces duff under the litter layer which explains the larger depth duffs observed at TSHE juvenile sites. Litter and duff 
layers were not measurable at sites where the juvenile was growing raised off the forest floor on a stump or nurse $\log$.

\section{Microsite Model Performance}

The BRT models were both relatively accurate in predicting presence based on microsite variables (Table 12). The TSHE model performed better than the THPL model based on results from confusion matrices. This was possibly due to the strong relationship between CWD substrate cover and TSHE juvenile presence. THPL juveniles appear to not be limited by substrate composition to the same degree at TSHE juveniles, therefore substrate cover variables were not influential in the THPL model. The deviation explained metric, which describes how well the model fit the data, was low for each model. This is not surprising as these models were built with only microsite level data and there are many other factors that influence presence of juveniles. However, the models were moderately successful in classifying testing data with misclassification rates ranging from $17-28 \%$. Cohen's kappa statistic was used to better assess model prediction performance since the model had a 50/50 chance of correctly classifying presence of a juvenile. The TSHE model produced at Kappa statistic of 0.67 which is rated as substantial and the THPL model produced a Kappa statistic of 0.44 which is rated as moderate (Landis \& Koch 1977).

The models confirmed trends observed in summarization of microsite variables between regeneration and control plots. The trends included the decreased presence of vegetation cover contributing to higher probability of presence of both species and the higher CWD cover contributing to higher probability of presence of TSHE juveniles. The model identified important interactions between microsite predictor variables which helps 
shed light on microsite dynamics impacting juvenile establishment (Figure 18). For example, the strongest interaction value was observed between fern and CWD coverdisplaying how CWD provides a safe site for juvenile establishment away from competing ferns. While the model performed moderately well, it could be improved with additional topographic and stand level variables of absence locations for each species.

\section{Stand Level Factors}

Stand composition and structure are important determinants of western hemlock and western red cedar regeneration but these factors have been heavily altered in Forest Park due to past disturbances (Broshot 2007; Schrader 1998). Sampled juveniles were established in stands ranging from mean densities of 200-300 trees/ha. These densities were typically lower than overall stand density measured in other studies within Forest Park, indicating that juvenile establishment and recruitment may be more successful in areas of lower stand density (Broshot 2007). Other studies have observed increased juvenile survival, growth, and recruitment in stands with decreasing overstory density (Dodson et al 2014; Maas-Hebner et al. 2005). Structural metrics such as tree density appear to impact the regeneration potential of shade-tolerant species but another perhaps more critical stand factor is the presence of shade-tolerant seed trees in the overstory.

Seed production and dispersal were not directly measured in this study but potential seed sources within the plot locations were tracked. Seed production and dispersal compose the first stages of conifer regeneration and the availability of seed producing trees greatly influences the regeneration potential of a given species in the stand (Dey et al 2020). The density of TSHE seed trees $(\mathrm{DBH}>30 \mathrm{~cm})$ at both species' sites was consistent among all 
units (15 - 20 trees/ha). TSHE juveniles were found more frequently in the north and referent units than in the south unit but the density of potential seed trees was consistent among all units. This emphasizes the importance of seed source-even when TSHE juveniles were scarce, they were located near older parent trees. Western hemlock seedling densities are strongly related to the abundance of mature overstory parent trees and stand age (Schrader 1998).

Stand structure and composition differed in the south and north units versus the reference Burlington unit. The prevalence of bigleaf maple in the two management units was a notable difference from the stand species composition in the reference unit. Bigleaf maple is commonly associated with Douglas fir-western hemlock forests in the PNW, but typically increases in abundance, particularly in riparian zones, during intermediate to late stages of succession (Niemiec 1995). Expansion of deciduous species such as bigleaf maple and red alder is also accelerated due to disturbances (Franklin \& Dynress 1988). Due to Forest Park's history of wildfires and clear-cut logging practices, the prevalence of bigleaf maple is not surprising. Pure bigleaf maple-dominated stands account for $33 \%$ of the area of the park, while $50 \%$ of the park is composed of a mix of bigleaf maple with conifer species. The increasing dominance of bigleaf maple in Forest Park could have negative impacts on recruitment of shade-tolerant conifers. Bigleaf maple has the capacity to grow rapidly when canopy gaps are created in overstory and outcompete the slower establishing shade-tolerant conifers for resources. Other studies have identified similar trends regarding bigleaf maple abundance in the park (Broshot 2007; Dresner et al. 2017). 
The density of standing dead (snag) trees was also much lower in the main park sections versus the reference site. The lack of snags present in the north and south units of the park is not surprising due to the younger age of the stand and history of clear-cut logging. Snags are important forest structural components for wildlife habitat, but eventually generate downed wood which is critical for the optimal microsite formation for western hemlock seedlings.

A study hypothesis was that canopy cover at juvenile locations would be lower than at corresponding controls. This was generally not the case at site locations. Mean canopy cover densities at were typically lower at regeneration plots compared to control plots for both species but not significantly lower (Table 8). This in part could be explained by study design as control plots were randomly placed $\sim 2$ meters away from the regeneration plot, which is not enough distance to observe differing canopy cover density. Increased light availability can lead to greater survival and growth of establishing juvenile shade-tolerant conifers (Wright et al. 1998; Weber et al. 2017). More data and experimental studies are needed to address the impacts of light availability and shade-tolerant conifer regeneration in Forest Park.

\section{Juvenile Vigor}

The different environmental factors associated with juvenile vigor were not clearly identified in this study. Live crown ratio typically fluctuated the most among vigor metrics with juveniles with higher vigor maintaining more live foliage and juveniles with low vigor associated with less foliage. It was hypothesized that higher vigor would be associated with larger canopy openings (decreased canopy cover), lower HLI and higher TWI. Of these 
hypotheses, decreased canopy cover generally followed the predicted trend. While not statistically significant, juveniles of both species in the AA vigor class had a mean canopy cover $\sim 96 \%$ while juveniles in the L vigor class had a mean canopy cover $\sim 98 \%$ (Table 10; $\mathrm{P}=0.3 ; \mathrm{P}=0.2$ ). More sample sizes would help to increase the statistical power of this trend, but nonetheless decreased canopy cover appear to be beneficial to juvenile vigor. Canopy openings or gaps are created when individual trees or groups of trees die. Openings in the canopy allow for increased light availability to reach the forest floor, potentially reaching established shade-tolerant juveniles. Higher growth rates, increased establishment, and survival rates for TSHE and THPL have been observed in canopy gaps compared to closedcanopy areas (Gray 1996).

Topographic indices HLI and TWI were not significant explanatory variables for juvenile vigor. It was hypothesized that low vigor would be associated at sites with higher HLI and lower TWI due to the influence of soil moisture availability and transpiration related stress. However, there were not substantial differences amongst these variables between vigor classes. Impacts from solar radiation and temperature are possibly mitigated in a closed canopy environment where overstory canopy shades the developing juveniles.

\section{Management Implications}

Implementing management practices to promote natural regeneration of western hemlock and western red cedar will be difficult in certain park sections due to the low abundance of seed source and relative lack of CWD present in Forest Park (Addessi 2017). Forest Park is composed of a patchwork of stands that vary in species composition, developmental/successional stage, and structure (McCallister et al. 2012; Broshot 2007). 
Some areas will be more feasible to manage towards old-growth conditions than others, such as mixed-conifer stands versus deciduous-dominated stands. Potential management actions to promote natural regeneration of shade-tolerant conifer species include protecting and retaining large seed trees of western hemlock and western red cedar as well as thinning early successional species such as bigleaf maple. Reducing overstory density in targeted areas could help release established shade-tolerant juveniles and accelerate the development of a multilayered, structurally complex canopy (Dodson et al 2014; MaasChan et al. 2006; Hebner et al. 2005, Bailey \& Tappeiner 1998). However, Forest Park is subject to regulatory limitations due to its status as a municipal city park, such that restoration practices involving individual tree removal may not be feasible, thus other restoration options may need to be considered.

There have been recent efforts to replant conifers seedlings in the Balch Creek watershed located within the south management unit. The results of this study can help guide future replanting efforts, specifically the microsite and stand level factors identified in this study (Table 5; Table 6) should be considered when searching for locations to plant juvenile conifers. While naturally regenerating western hemlock prefer CWD substrates, this may not be a requirement for transplants. Transplanted seedlings have completed the beginning stages of natural regeneration, therefore focusing on factors that affect survival and growth of juvenile transplants is most relevant. Transplants need to be planted in locations free of competing ferns and shrubs. Vegetation control techniques could be utilized in replanting areas. This includes targeted mechanical or chemical removal of competing understory vegetation in replanting zones. Canopy gaps and low density stand areas are also preferred locations for planting. Large canopy gaps are favorable for juvenile 
growth and recruitment and therefore need to be targeted for replanting efforts. Furthermore, if canopy gap creation via tree removal is not a feasible management action, then locating existing canopy gaps (See Appendix) to replant would achieve a similar outcome. Topography needs to be considered along with microsite and stand level factors as $58 \%$ of juveniles were observed on NW, $\mathrm{N}$ and $\mathrm{NE}$ facing slopes while these slope aspects account for $51 \%$ of the study area, indicating a habitat preference for these locations. Meanwhile, $22 \%$ of juveniles were observed on SE, SE and SW facing slope aspects which account for $30 \%$ of the study area.

Future transplants should be systematically planted and monitored to further to better understand multi-scale factors associated with seedling survival and growth. For example, comparing the success of planting transplant seedlings and sowing seeds in areas of dense ivy cover versus ivy removal areas will help to better managers gain a better understanding on the impacts of ivy to conifer regeneration in the park. Furthermore, planting seedlings in areas manually thinned to reduce overstory density could be monitored and compared to un-thinned controls to further determine whether selective thinning is an effective management option for increasing conifer regeneration.

While conifer regeneration is an important component of current management goals, there are competing management goals within Forest Park. Managers simultaneously seek to reduce risk of catastrophic wildfire while promoting the development of structurally complex forest conditions. The presence of deciduous trees may act as fire break due to their moisture retaining ability and help reduce fire risk (McAllister et al. 2011). Meanwhile, promoting shade-tolerant recruitment leading to a multilayered canopy could create hazardous ladder fuel conditions. Furthermore, while 
Forest Park follows its own city council approved natural resource management plan (NRMP) that established goals and plans for the park, it is still subject to Title 33 Environmental Zoning regulations for proposed activities not specifically described in the NRMP. These regulations can make certain management activities such as overstory tree removal difficult to implement (Johnson, personal communication, 2021). These competing goals and the strict regulatory environment in the park present a challenge for implementing certain restoration practices such as creating canopy gaps and thinning deciduous overstory density.

\section{Study Limitations}

This study did not directly measure seed production and dispersal. These are early and critical stages of the regeneration process that need to be taken in account when assessing current regeneration conditions in the park. However, the focus of this study was related to multi-scale growing conditions for juveniles therefore, missing the seed production and dispersal component did not impact overall research goals. Small sample sizes limited predictive model development for juvenile vigor, e.g., 8 low vigor samples for THPL. Due to their scarcity, seedlings $<5$ years old were largely missing in this study. The lack of young seedlings found could also be a result of observer bias as smaller seedlings are more difficult to detect on the forest floor. The targeted sampling approach allowed for efficient detection of target species but may be biased toward taller more visible juveniles. However, past studies with more conventional sampling designs have also identified a dearth of young shade-tolerant seedlings in the south unit (Broshot 2007), indicating the lack of young seedlings observed in this study is likely due to their scarcity 
rather than observer bias. This study combined seedling and sapling growth forms together in analysis. The dynamics of establishment, survival and growth can change as seedlings grow into saplings. For example, as taller saplings are less influenced by competitive pressures of understory vegetation and more sensitive to overstory density (Dodson et al. 2014). This study presents a more generalized view of shade-tolerant conifer regeneration habitat suitability in analyzing both growth forms together.

Belowground dynamics considering relationships between soil properties and ectomycorrhizal networks and juvenile establishment were not examined in this study. Mycorrhizal networks can facilitate western hemlock establishment and recruitment through carbon and other resource transfer (Christy et al. 1982; Orrego 2018). Other soil properties such as nutrients, $\mathrm{pH}$, and organic matter were not examined in this study. Future studies that include essential forest functional components such as soil and belowground dynamics are needed to better understand conifer regeneration dynamics in Forest Park.

\section{Future Considerations}

This study could improve with larger sample sizes of each species. The research questions relating to juvenile vigor were not fully answered in part because of low sample size collected in each vigor class. Repeated visits to juvenile locations to monitor survival, growth and whether they are successfully recruited into the stand would increase understanding of recruitment dynamics. More information is needed regarding seed production and dispersal in Forest Park. Installing seed traps in different park units in areas with ample shade-tolerant seed trees could help to determine whether current shadetolerant regeneration is limited by seed production and dispersal, microsite conditions, or 
other factors. Experimental approaches to restoration activities coupled with monitoring assessments need be implemented to provide further guidance to the effectiveness of proposed management options.

\section{Conclusion}

The results of this study conclude that multi-scale environmental factors impact shade-tolerant regeneration patterns in Forest Park and need to be considered when implementing restoration practices. At the microsite level, competitive understory vegetation dynamics appear to inhibit the establishment of juvenile conifers, as most were observed in areas of significantly lower fern cover. Most TSHE juveniles were found to be established on nurse $\operatorname{logs}$, indicating the importance of CWD as a critical substrate requirement for TSHE establishment. Meanwhile, THPL juveniles appear to be limited solely by understory vegetation cover, not by substrate composition. Additionally, the presence of adequate seed sources was critical for natural regeneration to occur within the park. Juveniles of both species were located near potential parent trees. While most juveniles were typically located on $\mathrm{N}, \mathrm{NW}$ and $\mathrm{NE}$ facing slopes, topography did not appear to impact overall juvenile vigor-larger sample sizes are needed to further explore patterns between topography and vigor. Decreased canopy cover and overstory density benefit juvenile vigor. Juveniles were observed more frequently in the north and reference unit than in the south unit. While the results of this study indicate that local environmental factors impact patterns of shade-tolerant conifer regeneration in the park, current impacts from urbanization and past land use practices may also have negative implications for the future regeneration potential of current stands in Forest Park. 
Past land use activities such as logging, and effects of urbanization have affected natural regeneration processes in the park. Past clear cuts have removed many legacy features, such as CWD and seed sources, required for natural regeneration of late succession species. Due to these land use factors, managing for structurally complex, multi-layered forests conditions that are consistent with old-growths forests will be a challenge for park managers. Protecting and developing seed trees of shade-tolerant species, as well as increasing the recruitment of shade-tolerant juveniles, will be important for promoting their natural regeneration. One promising technique to promote shadetolerant species is targeted thinning of deciduous species, such as bigleaf maples in areas around shade-tolerant seed trees and juveniles yet may not be feasible given the regulatory limitations in the park. If creating canopy gaps via tree removal is not feasible, locating existing canopy gaps to plant seedlings may be the most practical option. Ongoing replanting efforts need to consider microsite and stand level factors identified in this study when locating future locations for transplants.

Promoting regeneration of western hemlock and western red cedar will help accelerate structural complexity and steer stand development more consistent with oldgrowth conditions within Forest Park. However, natural regeneration processes have been altered due to novel disturbance regimes, resulting in stands that differ in forest structure and composition from historic analogues. These current stand conditions have implications for overall forest resilience and the ability of the park to provide important ecosystem services to the community. In addition to novel disturbance regimes introduced by urbanization and land use change, the future stand conditions of Forest Park will be driven by changes in local climate. As global temperatures continue to rise, Portland is estimated 
to have climate conditions similar to the current climate of Sacramento, California, by 2080, which would result in summers being $88 \%$ drier than current conditions (Fitzpatrick \& Dunn 2019). These projected changes to climate patterns, along with current evidence of western red cedar dieback in the region, present further challenges to urban forest managers in the PNW and reasons for concern regarding future forest resilience and composition in the region. The future composition of Forest Park will depend in part on current management intervention as well as innovative and adaptive restoration practices. 


\section{References}

Adams, D. L., \& Mahoney, R. L. (1991). Effects of shade and competing vegetation on growth of western redcedar regeneration. Western Journal of Applied Forestry, 6(1), 2122.

Bailey, J. D., \& Tappeiner, J. C. (1998). Effects of thinning on structural development in 40-to 100-year-old Douglas-fir stands in western Oregon. Forest Ecology and Management, 108(1-2), 99-113.

Balandier, P., Collet, C., Miller, J. H., Reynolds, P. E., \& Zedaker, S. M. (2006). Designing forest vegetation management strategies based on the mechanisms and dynamics of crop tree competition by neighbouring vegetation. Forestry, 79(1), 3-27.

Ballantyne, M., Gudes, O., \& Pickering, C. M. (2014). Recreational trails are an important cause of fragmentation in endangered urban forests: a case-study from Australia. Landscape and Urban Planning, 130, 112-124.

Beach, E. W., \& Halpern, C. B. (2001). Controls on conifer regeneration in managed riparian forests: effects of seed source, substrate, and vegetation. Canadian Journal of Forest Research, 31(3), 471-482.

Bolund, P., \& Hunhammar, S. (1999). Ecosystem services in urban areas. Ecological economics, 29(2), 293-301.

Broshot, N. E. (1999). The effects of urbanization and human disturbance upon plant community structure and bird species richness, diversity, and abundance in a natural forested area (Forest Park) in Portland, Oregon.

Broshot, N. E. (2007). The influence of urbanization on forest stand dynamics in Northwestern Oregon. Urban Ecosystems, 10(3), 285-298.

Buffo, J. (1973). Direct solar radiation on various slopes from 0 to 60 degrees north latitude. Pacific Northwest Forest and Range Experiment Station.

Caccia, F. D., \& Ballaré, C. L. (1998). Effects of tree cover, understory vegetation, and litter on regeneration of Douglas-fir (Pseudotsuga menziesii) in southwestern Argentina. Canadian Journal of Forest Research, 28(5), 683-692.

Chan, S. S., Larson, D. J., Maas-Hebner, K. G., Emmingham, W. H., Johnston, S. R., \& Mikowski, D. A. (2006). Overstory and understory development in thinned and underplanted Oregon Coast Range Douglas-fir stands. Canadian Journal of Forest Research, 36(10), 2696-2711. 
Christy, E. J., \& Mack, R. N. (1984). Variation in demography of juvenile Tsuga heterophylla across the substratum mosaic. The Journal of Ecology, 75-91.

City of Portland (1995). Forest Park Natural Resources Management Plan. Portland Parks and Recreation Bureau of Planning Portland, Oregon.

Christy, J. A., Alverson, E. R., Dougherty, M. P., Kolar, S. C., Alton, C. W., Hawes, S. M, ... Nielsen, E. M. (2008). Classification of historical vegetation in Oregon as recorded by General Land Office surveyors. Oregon: Oregon Natural Heritage Information Center, OSU

Christy, E. J., Sollins, P., \& Trappe, J. M. (1982). First-year survival of Tsuga heterophylla without mycorrhizae and subsequent ectomycorrhizal development on decaying logs and mineral soil. Canadian Journal of Botany, 60(9), 1601-1605.

Colangeli, A. M., \& Owens, J. N. (1990). Cone and seed development in a windpollinated, western hemlock (Tsuga heterophylla) clone bank. Canadian Journal of Forest Research, 20(9), 1432-1437.

Davis, K. T., Higuera, P. E., \& Sala, A. (2018). Anticipating fire-mediated impacts of climate change using a demographic framework. Functional ecology, 32(7), 1729-1745.

Dwyer, J. F., McPherson, E. G., Schroeder, H. W., \& Rowntree, R. A. (1992). Assessing the benefits and costs of the urban forest. Journal of Arboriculture. 18 (5): 227234., 18(5), 227-234.

Dwyer, J. F. (2000). Connecting people with ecosystems in the 21 st century: an assessment of our nation's urban forests (Vol. 490). US Department of Agriculture, Forest Service, Pacific Northwest Research Station.

De Voto, B. (Ed.). (1953). The journals of Lewis and Clark (p. 123). Boston: Houghton Mifflin.

Dey, D. C., Knapp, B. O., Battaglia, M. A., Deal, R. L., Hart, J. L., O'Hara, K. L., ... \& Schuler, T. M. (2019). Barriers to natural regeneration in temperate forests across the USA. New Forests, 50(1), 11-40.

Dodson, E. K., Burton, J. I., \& Puettmann, K. J. (2014). Multiscale controls on natural regeneration dynamics after partial overstory removal in Douglas-fir forests in western Oregon, USA. Forest Science, 60(5), 953-961.

Dresner, M., Van Winkle, J., \& Copp Franz, S. (2017). Tree composition and abundance patterns differ in two watersheds of Forest Park, a large Pacific Northwest urban forest. Arboricultural Journal, 39(4), 208-225. 
Evans JS, Oakleaf J, Cushman SA, Theobald D (2014). An ArcGIS Toolbox for Surface Gradient and Geomorphometric Modeling, version 2.0-0.

Feller, M. C., \& Klinka, K. (1998). Seedfall, seed germination, and initial survival and growth of seedlings of Thuja plicata in southwestern British Columbia. Northwest Science, 72(3), 157-169.

Fitzpatrick, M. C., \& Dunn, R. R. (2019). Contemporary climatic analogs for 540 North American urban areas in the late 21st century. Nature communications, 10(1), 1-7.

Franklin, J. F., \& Dyrness, C. T. (1988). Natural vegetation of Oregon and Washington. Corvallis, OR.

Franklin, J. F., \& Hemstrom, M. A. (1981). Aspects of succession in the coniferous forests of the Pacific Northwest. In Forest succession (pp. 212-229). Springer, New York, NY.

Franklin, J. F., Johnson, K. N., \& Johnson, D. L. (2018). Ecological forest management. Waveland Press.

Freund, J. A., Franklin, J. F., \& Lutz, J. A. (2015). Structure of early old-growth Douglas-fir forests in the Pacific Northwest. Forest Ecology and Management, 335, 11-25.

Frey, B. R., Ashton, M. S., McKenna, J. J., Ellum, D., \& Finkral, A. (2007). Topographic and temporal patterns in tree seedling establishment, growth, and survival among masting species of southern New England mixed-deciduous forests. Forest Ecology and Management, 245(1-3), 54-63.

Gashwiler, J. S. (1967). Conifer seed survival in a western Oregon clearcut. Ecology, 48(3), 431-438.

Gray, A. N. (2011). Characteristics of Remnant Old Growth Forests in the Northern Coast Range of Oregon and Comparison to Surrounding Landscapes. DIANE Publishing.

Gray, A. N., \& Spies, T. A. (1997). Microsite controls on tree seedling establishment in conifer forest canopy gaps. Ecology, 78(8), 2458-2473.

Gray, A. N., \& Spies, T. A. (1996). Gap size, within-gap position and canopy structure effects on conifer seedling establishment. Journal of ecology, 635-645.

Grubb, P. J. (1977). The maintenance of species-richness in plant communities: the importance of the regeneration niche. Biological reviews, 52(1), 107-145. 
Harrington, CA. (2020, December). Biology of Western Redcedar. [Conference Presentation] Cedar Summit: Discussion Redcedar Dieback on the Pacific Coast. Portland State University, Portland OR.

Harmon, M. E., \& Franklin, J. F. (1989). Tree seedlings on logs in Picea-Tsuga forests of Oregon and Washington. Ecology, 70(1), 48-59.

Harmon, M. E., Franklin, J. F., Swanson, F. J., Sollins, P., Gregory, S. V., Lattin, J. D., ... \& Cummins, K. W. (1986). Ecology of coarse woody debris in temperate ecosystems. Advances in ecological research, 15, 133-302.

Hovind, H. J., \& Rieck, C. E. (1961). Basal area and point-sampling. Wisconsin Department of Natural Resources Technical Bulletin, 23(16), 23-30.

Johnson, M. (2021). Personal Communication.

Kostel-Hughes, F., Young, T. P., \& Wehr, J. D. (2005). Effects of leaf litter depth on the emergence and seedling growth of deciduous forest tree species in relation toseed size1. The Journal of the Torrey Botanical Society, 132(1), 50-61.

Landis, J. R., \& Koch, G. G. (1977). The measurement of observer agreement for categorical data. biometrics, 159-174.

Lobo, N. (2014). Conifer seed predation by terrestrial small mammals: A review of the patterns, implications, and limitations of top-down and bottom-up interactions. Forest Ecology and management, 328, 45-54.

Maas-Hebner, K. G., Emmingham, W. H., Larson, D. J., \& Chan, S. S. (2005). Establishment and growth of native hardwood and conifer seedlings underplanted in thinned Douglas-fir stands. Forest Ecology and Management, 208(1-3), 331-345.

Myers, R. (2013) Greater Forest Park Conservation Initiative. Retrieved from: www.forestparkconservancy.org

McAllister, D., Dragoy, A., Moeller, D., Petersen-Morgan, K., Roth, E., Darling, J., Keyes, C. (2011). Forest Park Desired Future Conditions. Portland Parks and Recreation, Portland, Oregon.

Messier, C. (1993). Factors limiting early growth of western redcedar, western hemlock and Sitka spruce seedlings on ericaceous-dominated clearcut sites in coastal British Columbia. Forest Ecology and Management, 60(3-4), 181-206.

Minore, D. (1990). Thuja plicata Donn ex D. Don—western redcedar. Silvics of North America, 1, 590-600. 
Niemiec, S. S. (1995). Hardwoods of the Pacific Northwest.

Munger, T. T. (1960). History of Portland's Forest Park. Forest-Park Committee of Fifty.

Nowak, D. J., Crane, D. E., \& Stevens, J. C. (2006). Air pollution removal by urban trees and shrubs in the United States. Urban forestry \& urban greening, 4(3-4), 115-123.

Nowak, D. J., Randler, P. B., Greenfield, E. J., Comas, S. J., Carr, M. A., \& Alig, R. J. (2010). Sustaining America's urban trees and forests: a Forests on the Edge report. Gen. Tech. Rep. NRS-62. Newtown Square, PA: US Department of Agriculture, Forest Service, Northern Research Station. 27 p., 62.

Packee, E. C. (1990). Tsuga heterophylla (Raf.) Sarg. western hemlock. Silvics of North America, 1, 613-622.

Phalan, B. T., Northrup, J. M., Yang, Z., Deal, R. L., Rousseau, J. S., Spies, T. A., \& Betts, M. G. (2019). Impacts of the Northwest Forest Plan on forest composition and bird populations. Proceedings of the National Academy of Sciences, 116(8), 3322-3327.

Orrego, G. (2018). Western hemlock regeneration on coarse woody debris is facilitated by linkage into a mycorrhizal network in an old-growth forest (Doctoral dissertation, University of British Columbia).

Owens, J. N. (1995). Constraints to seed production: temperate and tropical forest trees. Tree Physiology, 15(7-8), 477-484.

Owens, John N., and Marje Molder. (1984). The reproductive cycles of western and mountain hemlock. British Columbia Ministry of Forests, Vancouver. 34 p.

Rother, M. T. (2015). Conifer regeneration after wildfire in low-elevation forests of the Colorado Front Range: implications of a warmer, drier climate (Doctoral dissertation, University of Colorado at Boulder).

Royo, A. A., \& Carson, W. P. (2006). On the formation of dense understory layers in forests worldwide: consequences and implications for forest dynamics, biodiversity, and succession. Canadian Journal of Forest Research, 36(6), 1345-1362.

Royo, A. A., \& Carson, W. P. (2008). Direct and indirect effects of a dense understory on tree seedling recruitment in temperate forests: habitat-mediated predation versus competition. Canadian Journal of Forest Research, 38(6), 1634-1645.

Schopmeyer, C. S. (1974). Seeds of woody plants in the United States (No. 450). Forest Service, US Department of Agriculture. 
Schrader, B. A. (1998). Structural development of late successional forests in the central Oregon Coast Range: abundance, dispersal, and growth of western hemlock (Tsuga heterophylla) regeneration.

Shiver, B. D., \& Borders, B. E. (1996). Sampling techniques for forest resource inventory. John Wiley and Sons.

Spies, T. A., Franklin, J. F., \& Klopsch, M. (1990). Canopy gaps in Douglas-fir forests of the Cascade Mountains. Canadian Journal of Forest Research, 20(5), 649-658

Spies, T. A., \& Franklin, J. F. (1996). The diversity and maintenance of old-growth forests. Biodiversity in managed landscapes. Oxford University Press, New York, New York, USA, 296-314.

Spies, T. A., Hibbs, D. E., Ohmann, J. L., Reeves, G. H., Pabst, R. J., Swanson, F. J., ... \& Schrader, B. A. (2002). The ecological basis of forest ecosystem management in the Oregon Coast Range. SD Hobbs, JP Hayes, 31-67.

Solecki, William D, Rosenzweig, Cynthia, Parshall, Lily, Pope, Greg, Clark, Maria, Cox, Jennifer, \& Wiencke, Mary. (2005). Mitigation of the heat island effect in urban New Jersey. Global Environmental Change. Part B, Environmental Hazards, 6(1), 39-49.

Stolte, K. (1996). Symptomology of ozone injury to pine foliage. In: Miller, Paul R.; Stolte, Kenneth W.; Duriscoe, Daniel M.; Pronos, John, technical coordinators. Evaluating ozone air pollution effects on pines in the western United States. Gen. Tech. Rep. PSW-GTR-155. Albany, CA: Pacific Southwest Research Station, Forest Service, US Department of Agriculture; p. 11-18, 155.

Turner, D. (1985). Successional Relationships and a Comparison of Biological Characteristics Among Six Northwestern Conifers. Bulletin of the Torrey Botanical Club, $112(4), 421$.

U.S. Department of Agriculture, Forest Service; U.S. Department of the Interior, Bureau of Land Management. 1994. Record of decision for amendments to Forest Service and Bureau of Land Management planning documents within the range of the northern spotted owl and standards and guidelines for management of habitat for latesuccessional and old-growth forest- related species within the range of the northern spotted owl. Portland, OR.

U.S. Forest Service (2020). Forest Inventory and Analysis National Core Field Guide (Volume 1: Field Data Collection Procedures for Phase 2 Plots). https://www.fia.fs.fed.us/library/field-guides-methods-proc/ 
Weber, A., Leckie, S., Kimmins, J. H., Gilbert, B., Blanco, J. A., \& Lo, Y. H. (2017). Survival and growth as measures of shade tolerance of planted western redcedar, western hemlock and amabilis fir seedlings in hemlock-fir forests of northern Vancouver Island. Forest ecology and management, 386, 13-21.

Wright, E. F., Coates, K. D., \& Bartemucci, P. (1998). Regeneration from seed of six tree species in the interior cedar-hemlock forests of British Columbia as affected by substrate and canopy gap position. Canadian journal of forest research, 28(9), 1352-1364. 


\section{Appendix A}

\section{Canopy Gap Analysis}

Canopy gap locations were identified in the south management unit to guide future replanting efforts. This analysis was conducted in ArcGIS Pro 2.5.2. Gaps were located using 2019 LiDAR data courtesy of DOGAMI. The highest hit and bare earth DEM raster datasets were subtracted to create a canopy height model. Next, the height values 1-20 ft and everything greater than $20 \mathrm{ft}$ in the height model were reclassified into two different classes. This raster output was converted into vector format using the Raster to Polygon tool. After the conversion, polygons in the canopy class (> $20 \mathrm{ft}$ ) were deleted and the remaining polygons are associated with canopy gaps. An attribute field for area was created and square feet was calculated for the canopy gaps. Gaps less than $100 \mathrm{ft}^{2}$ were selected and deleted and gaps created from powerlines, roads and trails were also deleted. The output from these methods created a polygon feature class containing canopy gaps greater than $100 \mathrm{ft}^{2}$ in the south management unit of Forest Park (Appendix, Figure 1).

To determine which of the identified canopy gaps were most suitable to replant conifers a weighted overlay analysis was completed using the gaps layer and topographic raster layers. Slope, heat load index (HLI), and topographic wetness index (TWI) were each clipped with the canopy gaps layer. Next, each of the topographic layers were reclassified. These layers were then used in a weighted overlay tool. On a 1-10 scale, lower values of slope $\left(<20^{\circ}\right)$ were scaled higher, lower values of $\operatorname{HLI}(<0.56)$ were scaled higher, and higher values of TWI (> 8.6) were scaled higher. TWI and HLI were weighted at $40 \%$ each and slope was weighted at $20 \%$. The final output displays most optimal canopy gaps 
to replant transplant conifers based on topography including lower HLI, higher TWI and lower slope (Appendix, Figure 2).

Figure 1. Canopy gap locations greater than $100 \mathrm{ft}^{2}$ in the South management unit of Forest Park.

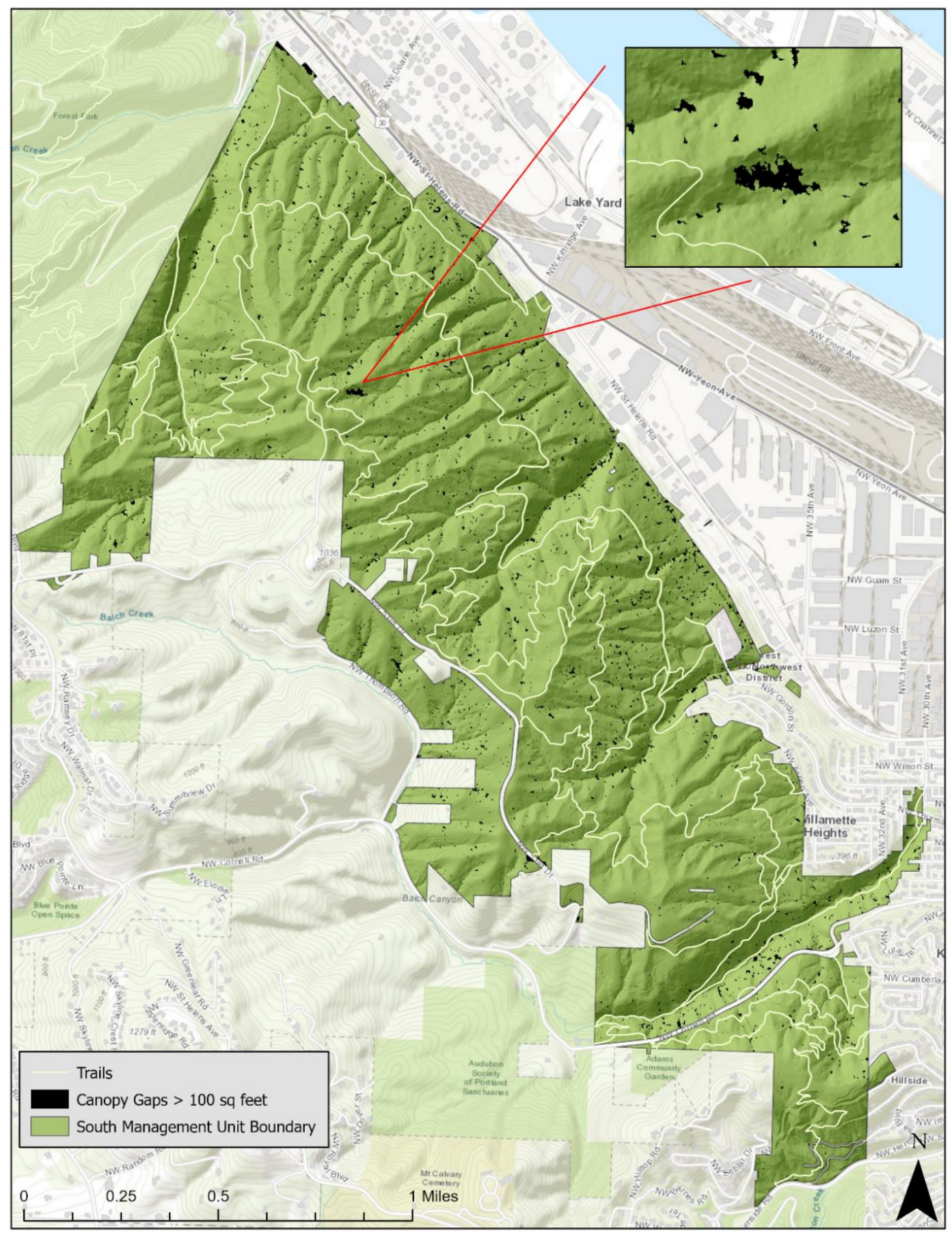




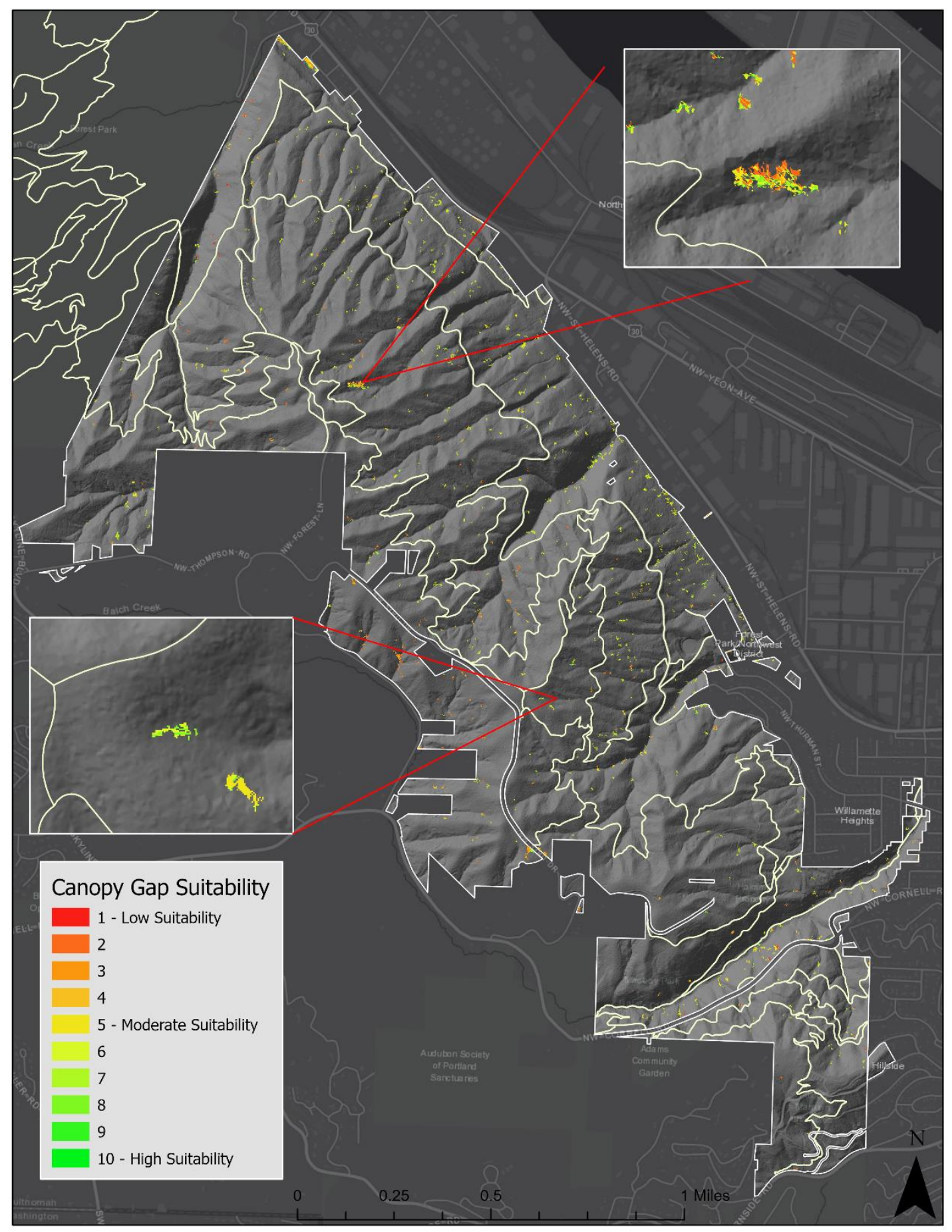

Figure 2. Canopy gap suitability analysis for replanting western hemlock and western red cedar juveniles. HLI, TWI and slope layers were clipped to canopy gaps layer and then a weighted overlay analysis was utilized to identify optimal canopy gaps to plant seedlings. 